\title{
CO-Releasing Molecule-2 Prevents Acute Kidney Injury through Suppression of ROS-Fyn-ER Stress Signaling in Mouse Model
}

\author{
Md Jamal Uddin (iD, Jeewon Jeong, Eun Seon Pak $(\mathbb{D}$, and Hunjoo Ha $(\mathbb{D}$ \\ Graduate School of Pharmaceutical Sciences, College of Pharmacy, Ewha Womans University, Republic of Korea \\ Correspondence should be addressed to Hunjoo Ha; hha@ewha.ac.kr
}

Received 11 March 2021; Revised 11 June 2021; Accepted 21 June 2021; Published 6 July 2021

Academic Editor: Alin Ciobica

Copyright (c) $2021 \mathrm{Md}$ Jamal Uddin et al. This is an open access article distributed under the Creative Commons Attribution License, which permits unrestricted use, distribution, and reproduction in any medium, provided the original work is properly cited.

\begin{abstract}
Acute kidney injury (AKI) most commonly appears in critically ill patients in hospitals. AKI is characterized as a quick deterioration of kidney function and has recently been identified to be tightly interlinked with chronic kidney diseases. The emerging major mediators of AKI include oxidative stress and endoplasmic reticulum (ER) stress. Carbon monoxide (CO) attenuates oxidative stress and ER stress in various cells, while Fyn, a member of the Src kinase family, is activated by oxidative stress and contributes to ER stress in skeletal muscle. Considering these, the objective of the current research was to determine (i) the involvement of Fyn in ER stress-mediated AKI and (ii) the effect of CO-releasing molecule-2 (CORM2) on reactive oxygen species- (ROS-) Fyn-ER stress-mediated AKI. Pretreatment with CORM2 (30 mg/kg) efficiently inhibited LPS (30 $\mathrm{mg} / \mathrm{kg}$ )-induced oxidative stress, inflammation, and cellular apoptosis during AKI in C57BL/6J mice. Also, CORM2 efficiently suppressed the activation of Fyn and ER stress in AKI mice. Consistently, pretreatment with CORM2 inhibited oxidative stress, Fyn activation, ER stress, inflammation, and apoptosis in LPS- or $\mathrm{H}_{2} \mathrm{O}_{2}$-stimulated proximal epithelial tubular cells. Fyn inhibition using siRNA or an inhibitor (PP2) significantly attenuated ER stress responses in the cells. These data suggest that CORM2 may become a potential treatment option against ROS-Fyn-ER stress-mediated AKI.
\end{abstract}

\section{Introduction}

Acute kidney injury (AKI) usually appears in hospital settings. The incidence rate of AKI is increasing, and it is accountable for nearly 2 million deaths per year worldwide [1]. Collective evidence suggests that patients with a history of AKI may develop chronic kidney diseases (CKD) $[2,3]$. AKI often occurs in the setting of sepsis [4]. The pathophysiology of AKI is complex and includes inflammation, tubular injury, and vascular damage $[5,6]$. Also, AKI can be mediated by dysregulation of the immune system, cell death or apoptosis, mitochondrial dysfunction, oxidative stress, and endoplasmic reticulum (ER) stress [7, 8]. Importantly, increased levels of reactive oxygen species (ROS) are linked with ER stress $[9,10]$. Although the pathophysiology of AKI has been studied, many targeted clinical therapies have failed [11]. Thus, urgent interventions are needed to treat AKI patients in the intensive care unit [12].
ER stress comprises a cellular process that is prompted by a variety of circumstances. ER stress is associated with the activation of three main ER stress sensors including inositol-requiring enzyme 1 (IRE1), activating transcription factor 6 (ATF6), and RNA-dependent protein kinase-like ER kinase (PERK). The activated IRE1 promotes X-boxbinding protein 1 (XBP1) cleavage to make spliced XBP1 (sXBP1) [13]. The activated XBP1 stimulates inflammatory cytokine production [14]. Also, during ER stress, IRE1 promotes JNK activation [15], which leads to cellular apoptosis. Various studies have suggested that inhibition of ER stress may fight against AKI [16-18].

Src family kinases (SFKs) belong to nonreceptor protein tyrosine kinases. Yet, there are eight members of SFK including Blk, c-Src, Fgr, Fyn, Hck, Lck, Lyn, and Yes. Some of them (c-Src, Fyn, and Yes) express ubiquitously, and others (Blk, Fgr, Hck, Lck, and Lyn) are primarily found in hematopoietic cells. Among all of these, Fyn, a $59 \mathrm{kDa}$ protein, has 
been known to regulate various cellular functions including cellular growth, survival, adhesion, motility, T-cell receptor signaling, and cytoskeletal remodeling [19-21]. The Fyn kinase has been considered a critical regulator of a variety of pathological conditions, including progressive CKD [22, 23]. Fyn has been reported to promote ER stress as well as subsequent activation of the IRE $1 \alpha$-JNK pathway, driving cell death in skeletal muscle [24]. However, the involvement of Fyn in ER stress-mediated AKI has not been studied.

Carbon monoxide (CO), an endogenous gas produced from heme degradation by heme oxygenase, shows protective functions in various pathological conditions [25-29]. CO inhibits ROS-mediated oxidative stress in human airway smooth muscle cells, human pulmonary alveolar epithelial cells, lens epithelial cells, and embryonic cells [30-34]. Also, $\mathrm{CO} / \mathrm{CO}$-releasing molecules (CORMs) suppress ER stress in endothelial cells and islet cells $[35,36]$. In the mouse kidney, CO protects against obstruction-induced fibrosis [37]. Also, CO/CORMs can be advantageous for treating AKI $[38,39]$. Importantly, the findings of our recent study suggested that CORM2 protects lipopolysaccharides- (LPS-) induced AKI through inhibition of ER stress in mice [16]. Yet, the detailed molecular mechanism involved in the protective effects of $\mathrm{CO}$ against ER stress-mediated AKI remains elusive.

Since CO attenuates oxidative stress and ER stress, and since Fyn contributes to ER stress, the aim of the current research was to verify (i) the involvement of Fyn in ER stress-mediated AKI and (ii) the effect of CORM2 on ROSFyn-ER stress signaling in AKI.

\section{Materials and Methods}

2.1. Materials. Chemicals and reagents were purchased from Sigma-Aldrich (St. Louis, MO, USA), unless otherwise stated.

2.2. Animals. Approval for animal studies was obtained from the institutional animal care and use committee (IACUC No. 16-055) of Ewha Womans University. Six-week-old male C57BL/6 mice (Japan SLC Inc., Hamamatsu, Japan) were divided into six groups: control, CORM2, PP2, LPS, LPS +CORM2, and LPS+PP2. Mice were pretreated with CORM2 (30 mg/kg, intraperitoneal, i.p.) or PP2 (2 mg/kg, i.p.) for $2 \mathrm{~h}$ and then subjected to administration of $15 \mathrm{mg} / \mathrm{kg}$ LPS (a sin-

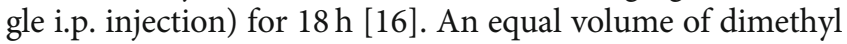
sulfoxide (DMSO) and saline as the vehicle of CORM2/PP2 and LPS, respectively, were injected into the control mice. All mice were sacrificed at $18 \mathrm{~h}$ after injection of LPS via anesthesia with $16.5 \%$ urethane $(10 \mathrm{ml} / \mathrm{kg})$. After anesthesia, blood was collected in a heparin-coated syringe. After perfusion with phosphate-buffered saline (PBS), the left kidneys were washed, weighed, and then kept for further studies. The right kidneys were subjected to $2 \%$ paraformaldehydelysine-periodate fixation at $\mathrm{pH} 7.4$ and then stored at room temperature for further study.

2.3. Blood Parameters. Blood plasma was obtained after centrifuging the blood samples at $900 \mathrm{~g}$ for $15 \mathrm{~min}$ at $4^{\circ} \mathrm{C}$. The levels of plasma creatinine were measured using a
DetectX Serum Creatinine Detection Kit (Arbor Assays, Ann Arbor, MI, USA). The plasma kidney injury molecule1 (KIM1, MKM100, R\&D Systems) and cystatin C (R\&D Systems, Minneapolis, MN, USA) levels were determined using enzyme-linked immunosorbent assay (ELISA) kits. The thiobarbituric acid reaction was used to measure the levels of plasma lipid hydroperoxide (LPO) as described [40].

2.4. Kidney LPO. The kidney LPO was measured according to the protocols of the kit manufacturer (Cayman Chemical Co, Ann Arbor, MI, USA).

2.5. Histology and Immunohistochemistry. The paraffinembedded kidney sections were then stained with a periodic acid-Schiff (PAS) reagent. Immunohistochemistry for antiF4/80 (1:200; Santa Cruz Biotechnology, Inc., Santa Cruz, CA, USA), anti-nitrotyrosine (1:200; Santa Cruz Biotechnology), anti-NADPH oxidase 2 (NOX2, 1:500), and antiNADPH oxidase 4 (NOX4, 1:300) antibodies was performed. A Zeiss microscope having an Axio cam HRC digital camera and software (Carl Zeiss, Thornwood, NY, USA) was utilized to take the images.

2.6. Immunofluorescence Staining. After deparaffinization and rehydration, tissue sections were incubated with retrieval solution and heated in a microwave to recover antigenicity. Nonspecific binding was blocked with serum-free blocking solution for $30 \mathrm{~min}$ at room temperature. Kidney sections were then incubated with anti-pFyn ( $1: 100$; Santa Cruz Biotechnology) or anti-p-Src (1:100; Cell Signaling Technology, Danvers, MA, USA) overnight at $4^{\circ} \mathrm{C}$. Tissue sections were incubated for $1 \mathrm{~h}$ with Alexa 488-conjugated goat antimouse (1:1000; Invitrogen, Carlsbad, CA, USA) or Alexa 568-conjugated goat anti-rabbit ( $1: 1000$; Invitrogen) antibodies. Cell nuclei were detected with $4^{\prime}, 6$-diamidino-2-phenylindole ( $1: 1000$; Thermo Fisher Scientific, Waltham, MA). Images were captured by a Zeiss ApoTome Axiovert 200M microscope (Carl Zeiss Microscopy GmbH, 07745, Jena, Germany).

2.7. Direct Measurement of ROS. To determine the presence of ROS, the frozen sections of the kidney were stained for $10 \mathrm{~min}$ at $37^{\circ} \mathrm{C}$ with $5 \mu \mathrm{M}$ dihydroethidium (DHE, red fluorescence at $561 \mathrm{~nm}$, Molecular Probes, Eugene, Oregon, USA) and then stained with 4',6-diamidino-2-phenylindole (DAPI). A Zeiss ApoTome Axiovert 200M microscope (Carl Zeiss, Germany) was used to take the images.

2.8. Cell Culture. Mouse proximal tubular epithelial (mProx24) cells were cultured in Dulbecco's modified Eagle's medium (DMEM) as described [41]. The cultured cells were stimulated with LPS in a time-dependent manner $(0,3,6,12$, and $24 \mathrm{~h})$. Also, the cells were treated with CORM2 $(0,5,10$, and $20 \mu \mathrm{M}), 10 \mu \mathrm{M}$ of PP2, $5 \mathrm{mM} \mathrm{N}$-acetylcysteine (NAC), and $1 \mathrm{mM} 4$-phenylbutyrate (4-PBA) for $2 \mathrm{~h}$ and then stimulated with LPS $(100 \mathrm{ng} / \mathrm{ml})$ for $6 \mathrm{~h}$ or $18 \mathrm{~h}$.

siRNAs were purchased from Bioneer corporation (Daejeon, South Korea). The mProx 24 cells $\left(5 \times 10^{5} / \mathrm{ml}\right)$ were cultured in six-well plates for $6 \mathrm{~h}$ and then transfected with Src siRNA $(100 \mathrm{nM})$ or Fyn siRNA (100 nM), using 
Lipofectamine 2000 according to the manufacturer's instructions. After transfection, the cells were starved by replacing the medium with DMEM containing $0.5 \%$ bovine serum albumin. The cells were then treated with LPS $(100 \mathrm{ng} / \mathrm{ml})$ for $6 \mathrm{~h}$ with or without pretreatment with CORM2 $(20 \mu \mathrm{M})$.

\subsection{Terminal Transferase-dUTP-Nick-End Labeling} (TUNEL) Assays. Apoptosis was measured using the TUNEL assay according to the manufacturer's protocol (Roche Diagnostics, Mannheim, Germany). First, after deparaffinization and rehydration, the kidney tissue was washed with PBS and then incubated with TUNEL reaction mixture for 60 min at $37^{\circ} \mathrm{C}$ in a humidified chamber at dark conditions. Kidney sections were subsequently washed with PBS and stained with DAPI. Images were analyzed by the Zeiss ApoTome Axiovert 200M microscope (Carl Zeiss, Germany).

In the case of mProx cells, the cultured cells in 6-well plates were treated with the mentioned reagents and then washed with $1 x$ PBS $(\times 2)$. After fixation and permeabilization, the cells were incubated with TUNEL reaction mixture for $60 \mathrm{~min}$ at $37^{\circ} \mathrm{C}$ followed by DAPI in a humidified dark chamber. Cells were subsequently washed with 1x PBS (×3) and analyzed using a Zeiss ApoTome Axiovert 200M microscope (Carl Zeiss, Germany).

2.10. Intracellular ROS Analysis. Intracellular ROS was measured in mProx cells according to our previous study with some modifications [42]. Briefly, the cells were washed with PBS $(\times 3)$ and incubated for $30 \mathrm{~min}$ in the dark at $37^{\circ} \mathrm{C}$ PBS containing $20 \mu \mathrm{M}$ DCF-DA (Abcam, Cambridge, MA). Fluorescence of oxidized DCF was detected using a Zeiss ApoTome Axiovert 200M microscope (Carl Zeiss, Germany) at excitation wavelengths of $485 \mathrm{~nm}$. The mean relative fluorescence intensity was measured by the average of five random values.

2.11. Real-Time RT-PCR Analysis. Real-time RT-PCR analysis for the whole kidney and mProx 24 cells was performed as described previously [16]. Briefly, total RNA was isolated using the TRIzol reagent (Life Technologies, Carlsbad, CA, USA), and then, cDNA was synthesized. The mRNA expression of various genes was determined by real-time RT-PCR using an ABI7300 system (Applied Biosystems, Carlsbad, CA, USA). The primer sequences are shown in Table 1.

2.12. Western Blot Analysis. The protein expression was determined using Western blot analysis as described [16]. Briefly, the kidney tissue and cell lysates were separated on SDS-polyacrylamide gel electrophoresis followed by transfer to polyvinylidene difluoride membranes. Then, the membranes were incubated with various antibodies including anti-p-eIF $2 \alpha$ (1:5000, Cell Signaling Technology), anti-pIRE1 $\alpha$ (1:4000, Santa Cruz Biotechnology), ATF6 $\alpha$ (1: 5000, Cell Signaling Technology), anti-pJNK (1:5000, Cell Signaling Technology), anti-CHOP (1:1000, Santa Cruz Biotechnology), anti-pSrc ( $1: 1000$; Cell Signaling Technology), anti-pFyn (1:1000; Santa Cruz Biotechnology), and anti- $\beta$ actin $(1: 1000)$ overnight at $4^{\circ} \mathrm{C}$ on a shaker. Then, the membranes were incubated with respective secondary antibodies, washed, and reacted with an enhanced chemiluminescent
TABle 1: Primers used for real-time RT-PCR analysis.

\begin{tabular}{|c|c|}
\hline $\begin{array}{l}\text { Gene } \\
\text { (mouse) }\end{array}$ & Primer sequences \\
\hline CAT & $\begin{array}{l}\text { F 5' -CACACCTACACGCAGGCCGG-3' } \\
\text { R 5' -CTGCGCTCCGGAGTGGGAGA-3' }\end{array}$ \\
\hline Edem 1 & $\begin{array}{c}\text { F } 5^{\prime} \text {-TGGGTTGGAAAGCAGAGTGGC-3' } \\
\text { R 5 }{ }^{\prime} \text {-TCCATTCCTACATGGAGGTAGAAGGG-3 }\end{array}$ \\
\hline Fyn & $\begin{array}{l}\text { F 5' -CTTTGGGGGTGTGAACTCCT-3' } \\
\text { R 5' -TTCTGCCTGGATGGAGTCAA-3 }\end{array}$ \\
\hline Hck & $\begin{array}{l}\text { F } 5^{\prime} \text {-AGGGGTTAGGACTGGGAACA-3' } \\
\text { R } 5^{\prime} \text {-CCCCAGAGATTTTGGACCCC-3 }\end{array}$ \\
\hline iNOS & $\begin{array}{l}\text { F 5'-ATGTCCGAAGCAAACATCAC-3' } \\
\text { R 5'-TAATGTCCA GGAAGTAGG TG-3' }\end{array}$ \\
\hline ICAM1 & $\begin{array}{c}\text { F } 5^{\prime} \text {-TGCCTCGGGAATGGAAAG-3' } \\
\text { R 5'-ATGGTAGTCTCCCCATCGTCATA-3' }\end{array}$ \\
\hline GRP78 & $\begin{array}{l}\text { F 5'-AGCCATTGGATCACAACCTC-3' } \\
\text { R 5'-AGAAGCGAGAGATCCATCCA-3' }\end{array}$ \\
\hline Lck & $\begin{array}{l}\text { F } 5^{\prime} \text {-ACGATCTCGGGGATCATGG-3' } \\
\text { R 5 '-GAGATCTTGCTGTCCAGTGGG-3' }\end{array}$ \\
\hline Lyn & $\begin{array}{l}\text { F 5'-AGCTCCAGAGGCCATCAACT-3' } \\
\text { R 5'-CACATCTGCGTTGGTTCTCC-3' }\end{array}$ \\
\hline c-Src & $\begin{array}{l}\text { F } 5^{\prime} \text {-TCCACACCTCTCCGAAGCAA-3' } \\
\text { R 5 }{ }^{\prime} \text {-CATGCTGATGGCCTGTGTCA-3' }\end{array}$ \\
\hline NQO1 & $\begin{array}{l}\text { F 5'-TTCTCTGGCCGATTCAGAG-3' } \\
\text { R 5 } 5^{\prime} \text {-GGCTGCTTGGAGCAAAATAG-3' }\end{array}$ \\
\hline Prx1 & $\begin{array}{l}\text { F 5'-TGGCCAACGAAGGGGTTAAA-3' } \\
\text { R 5'-GATGAGGCTGCAGTTGAGGT-3' }\end{array}$ \\
\hline sXBP1 & $\begin{array}{c}\text { F 5'-GAGTCCGCAGCAGGTG-3' } \\
\text { R 5'-GTGTCAGAGTCCATGGGA-3' }\end{array}$ \\
\hline $\mathrm{TNF} \alpha$ & $\begin{array}{l}\text { F } 5^{\prime} \text {-CGTCAGCCGATTTGCTATCT-3' } \\
\text { R 5 }{ }^{\prime} \text {-CGGACTCCGCAAAGTCTAAG-3' }\end{array}$ \\
\hline $18 \mathrm{~S}$ & $\begin{array}{l}\text { F 5' -CGAAAGCATTTGCCAAGAAT-3' } \\
\text { R 5 }{ }^{\prime} \text {-AGTCGGCATCGTTTATGGTC-3' }\end{array}$ \\
\hline
\end{tabular}

F: forward; R: reverse.

sensitive plus reaction (BioFX Laboratories, Inc., Owings Mills, MD, USA). The bands were quantified by using ImageJ software and normalized by $\beta$-actin.

2.13. Statistical Analysis. All results were expressed as the mean \pm standard error (SE). The statistical differences among the groups were evaluated by one-way ANOVA and subsequent Fisher's post hoc analysis. Differences were considered to be significant when $p<0.05$.

\section{Results}

3.1. CORM2 Improves Kidney Function and Attenuates Kidney Tubular Injury. We first showed that LPS significantly decreased body weight in a time-dependent manner (Supplementary Fig. 1A). Pretreatment with CORM2 significantly inhibited the LPS-induced decrease in body weight 

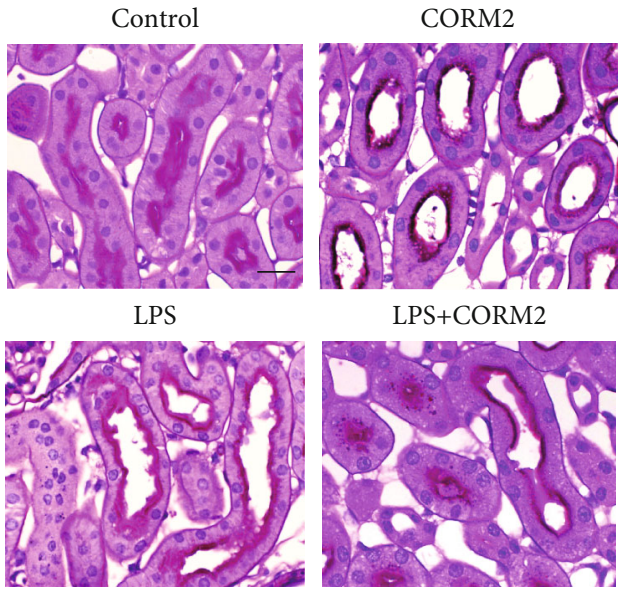

LPS+CORM2

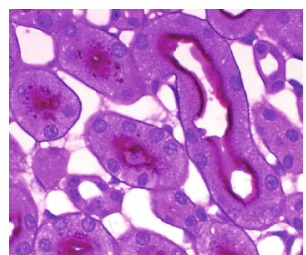

(a)

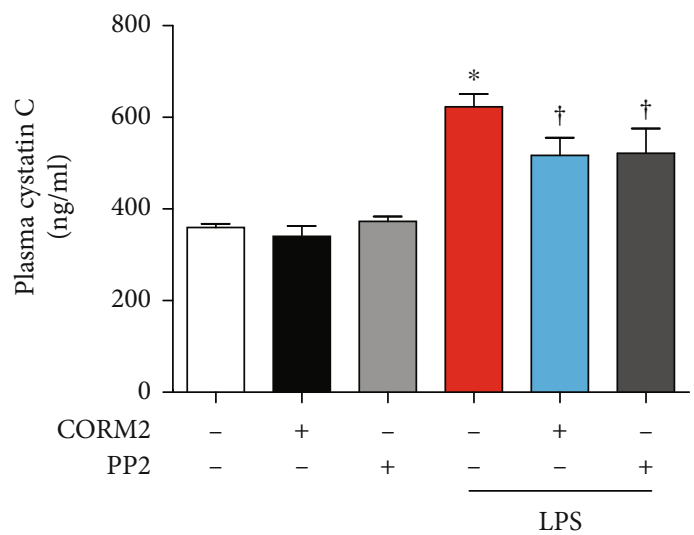

(c)

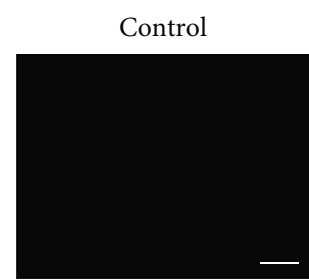

LPS

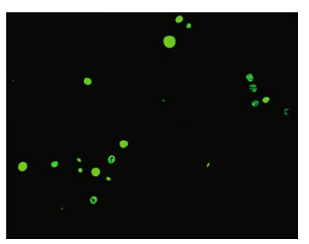

PP2

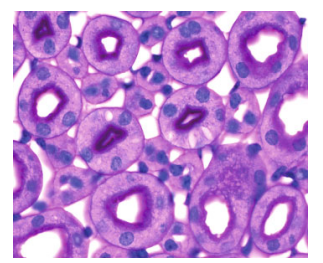

LPS+PP2
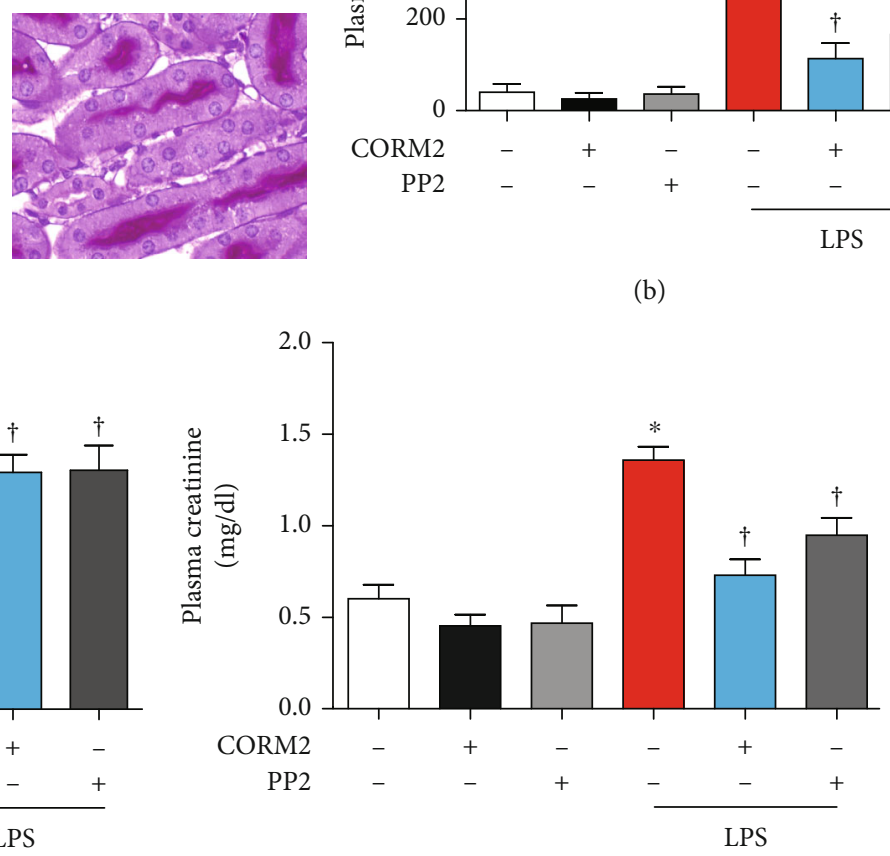

(d)

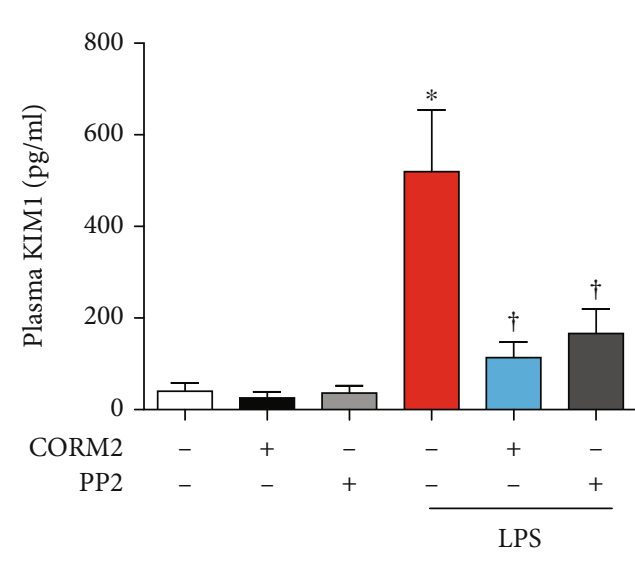

(b)
CORM2

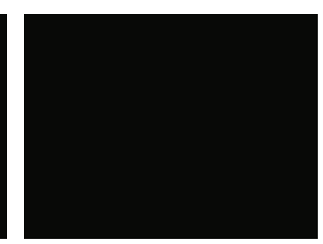

LPS+CORM2

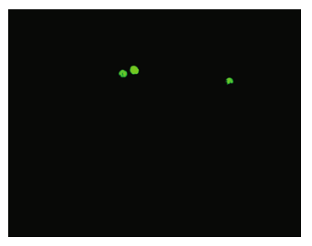

(e)

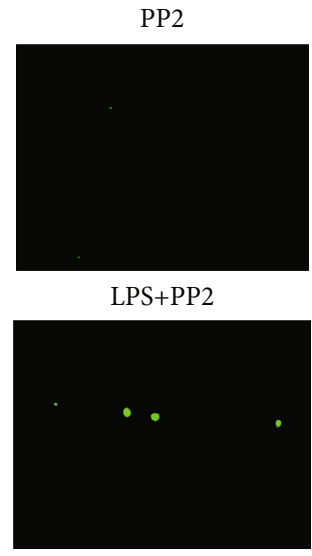

FIgURe 1: CORM2 reduces LPS-induced kidney dysfunction and injury in mice. Mice were pretreated with CORM2 (30 mg/kg) or PP2 (2 $\mathrm{mg} / \mathrm{kg}$ ) for $2 \mathrm{~h}$ and then administrated with LPS $(15 \mathrm{mg} / \mathrm{kg}$ ) for $18 \mathrm{~h}$. (a) Paraffin-embedded kidney sections were stained with PAS (magnification: 630x; scale bar: $20 \mu \mathrm{m}$ ). Blood plasma was used to determine (b) KIM1 (pg/ml), (c) cystatin C (ng/ml), and (d) creatinine $(\mathrm{mg} / \mathrm{dl})$. (e) Apoptosis was measured in paraffin-embedded kidney sections using TUNEL assays (magnification: 400x; scale bar: $100 \mu \mathrm{m}$ ). Data are presented as means $\pm \mathrm{SE}$, control $(n=8)$, CORM2 $(n=8)$, PP2 $(n=8)$, LPS $(n=6-8)$, LPS+CORM2 $(n=6-8)$, and LPS+PP2 $(n=6-8) ;{ }^{*} p<0.05$ vs. control, ${ }^{\dagger} p<0.05$ vs. LPS.

and the kidney to body weight (Supplementary Fig. 1B-C). Then, we examined the effect of CORM2 on kidney function and morphology changes during LPS-induced AKI. The results of PAS staining (Figure 1(a)) showed tubular damage in the LPS-induced AKI mice, which was ameliorated by
CORM2 or PP2. Also, CORM2 or PP2 treatment significantly inhibited the LPS-induced plasma KIM1 levels in the AKI mice (Figure 1(b)). CORM2 or PP2 significantly decreased LPS-induced plasma cystatin C (Figure 1(c)) and creatinine (Figure 1(d)) levels, suggesting that CORM2 may 


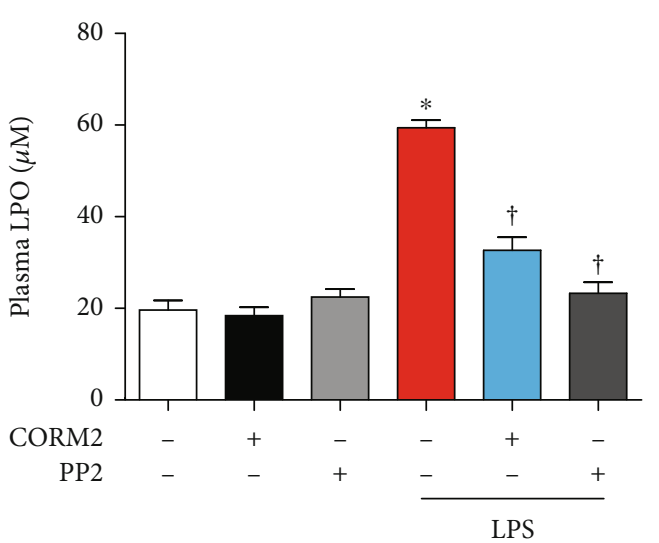

(a)
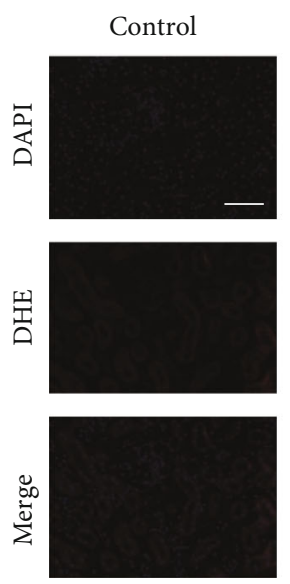

Control

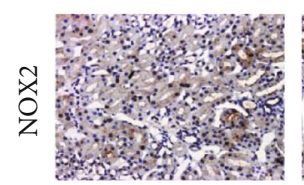

CORM2
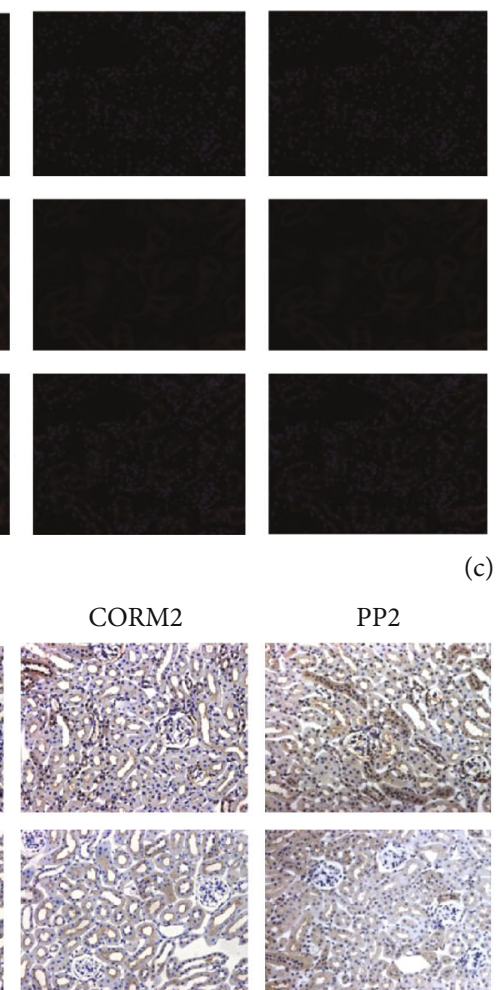

(c)

Control

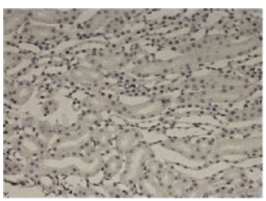

LPS

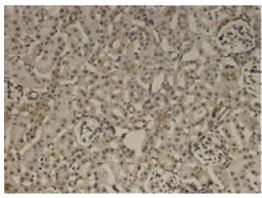

P2
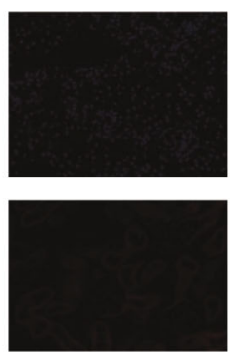

PP2

LPS
CORM2

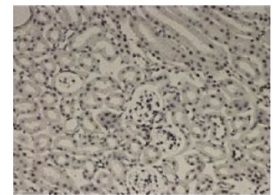

LPS+CORM2

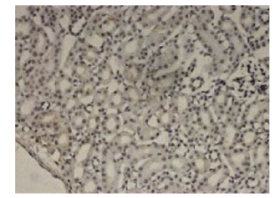

(b)

LPS+CORM2
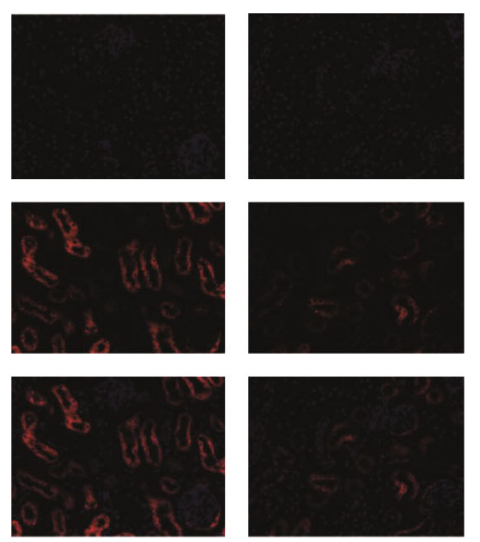
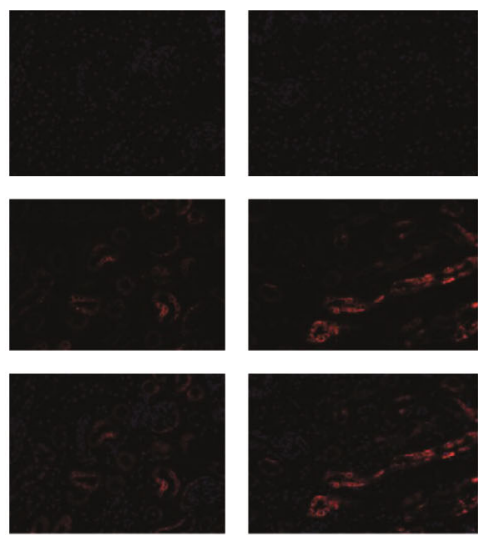

LPS+CORM2

LPS+PP2
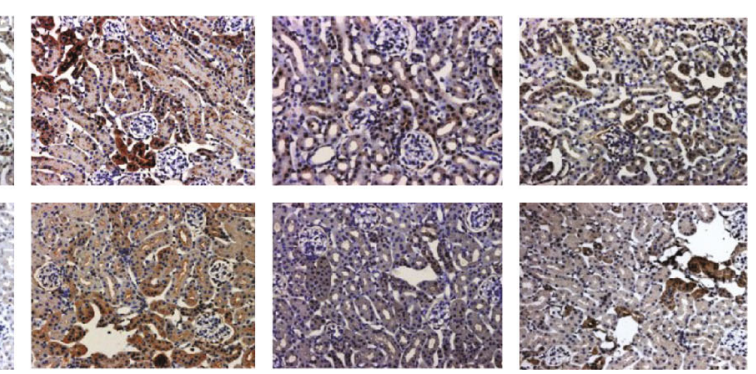

(d)

Control

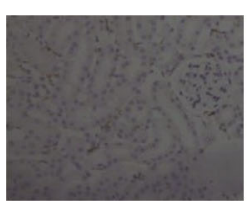

CORM2

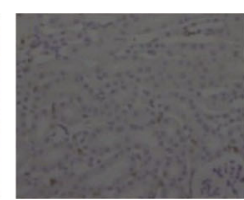

PP2

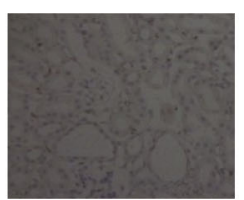

LPS

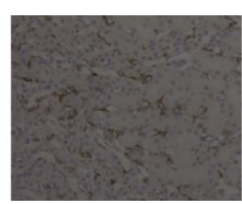

(e)
LPS+CORM2

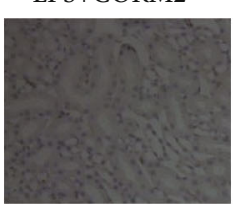

LPS+PP2

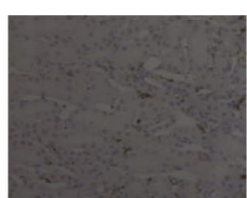

Figure 2: Continued. 


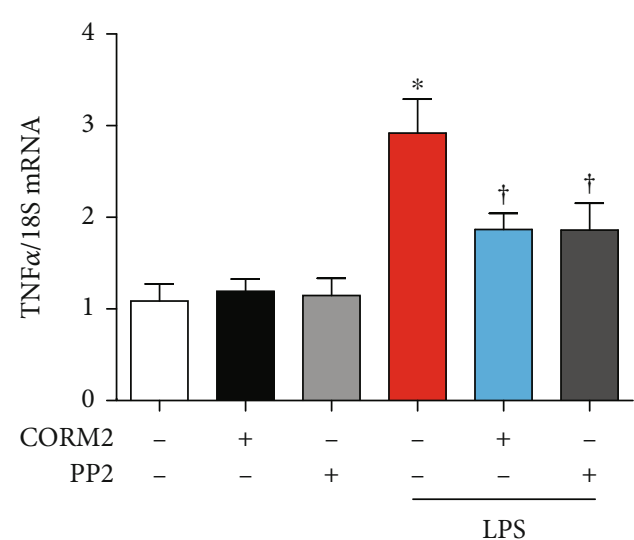

(f)

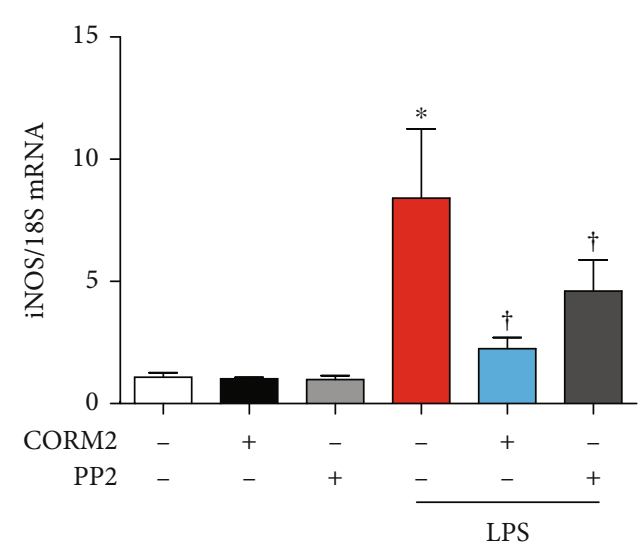

(g)

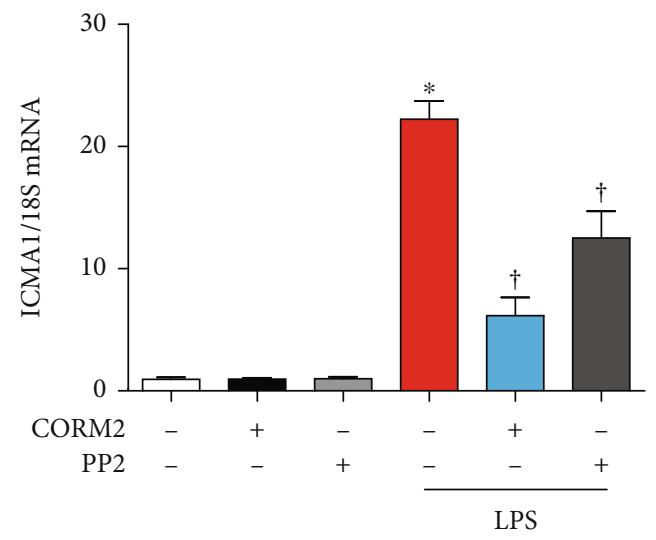

(h)

FIGURE 2: CORM2 reduces kidney oxidative stress and inflammation in LPS-induced AKI mice. (a) Blood plasma was used to determine LPO $(\mu \mathrm{M})$. (b) Anti-nitrotyrosine antibody $(1: 200)$ was used to stain the paraffin sections of the kidney, and accumulation of nitrotyrosine is shown in the cytosol (brown color). (c) DHE $(5 \mu \mathrm{M}$ for $10 \mathrm{~min}$ ) was used to stain the frozen sections of the kidney, and the red color indicates ROS accumulation. Magnification: 100x; scale bar: $50 \mu \mathrm{m}$. (d, e) Paraffin sections of the kidney were incubated with (d) anti-NOX2 (1:500) and anti-NOX4 (1:400) and (e) anti-F4/80 (1:200) antibodies. Magnification of all images from paraffin sections: 100x; scale bar: $100 \mu \mathrm{m}$. (f-h) Real-time RT-PCR was used to measure the mRNA levels of TNF $\alpha$, iNOS, and ICAM1 in the kidney. Data are presented as means \pm SE, control $(n=8)$, CORM2 $(n=8)$, PP2 $(n=8)$, LPS $(n=6-8)$, LPS+CORM2 $(n=7-8)$, and LPS+PP2 $(n=6-8) ;{ }^{*} p<0.05$ vs. control, ${ }^{\dagger} p<0.05$ vs. LPS.

enhance kidney function in AKI mice. Cellular apoptosis was detected using TUNEL assays. TUNEL-positive cells were markedly increased in the LPS-induced AKI mice, and the number was decreased by CORM2 or PP2 (Figure 1(e)).

\subsection{CORM2 Attenuates LPS-Induced Kidney Oxidative Stress} and Inflammation. Oxidative stress is an important contributor to the pathogenesis of AKI [43]. First, we have confirmed the time-dependent effects of LPS on antioxidants. Expression of NRF2 and NQO1 mRNA was effectively decreased at 12 and $24 \mathrm{~h}$ after injection of LPS (Supplementary Fig. 3C). Plasma LPO was significantly increased in LPS-induced AKI mice, which was effectively inhibited by CORM2 or PP2 (Figure 2(a)). LPS-induced accumulation of nitrotyrosine in the kidney was also considerably inhibited by CORM2 or PP2 (Figure 2(b)).

To precisely measure ROS in kidney tissues, DHE staining was accomplished. LPS effectively enhanced ROS levels, which were significantly reduced by CORM2 or PP2 (Figure 2(c)). The expression levels of NOX2 and NOX4 as measured by immunostaining were significantly increased in LPS-induced AKI mice. Interestingly, these changes were significantly hindered by CORM2 or PP2 (Figure 2(d)). Also, the NOX2 and NOX4 mRNA levels were significantly decreased by CORM2 in AKI mice (Supplementary Fig. 3E-F). Together, these data suggest that CORM2 decreases oxidative stress as much as PP2 does in LPS-induced AKI.

Since inflammation is critically involved in AKI, we determined whether CORM2 or PP2 has an anti-inflammatory effect on LPS-induced AKI. First, we confirmed the timedependent effects of LPS on proinflammatory genes. As expected, proinflammatory genes were significantly increased at various time points by both agents in the mice (Supplementary Fig. 3A). LPS effectively increased the staining of F4/80, a marker of macrophage infiltration, which was significantly reduced by treatment of CORM2 or PP2 in the kidneys (Figure 2(e)). Likely, CORM2 significantly reduced LPSinduced mRNAs of proinflammatory cytokines including $\mathrm{TNF} \alpha$, iNOS, and ICAM1 in the kidneys (Figure 2(f)-2(h)). 


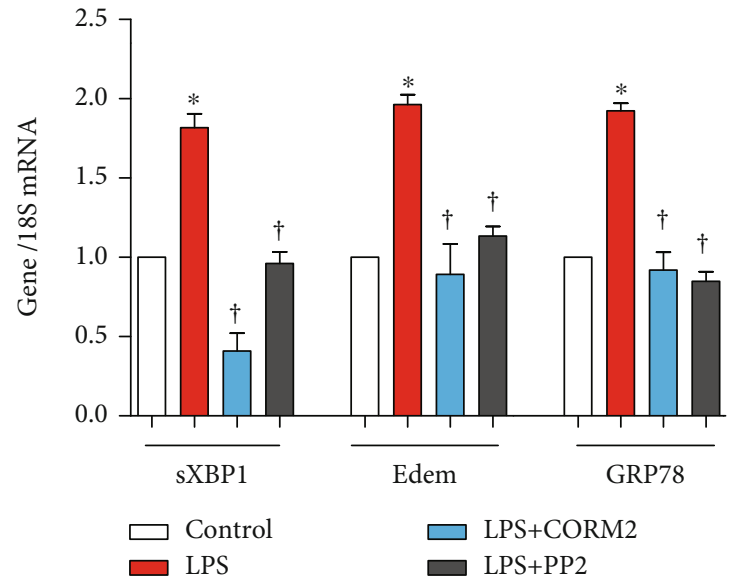

(a)

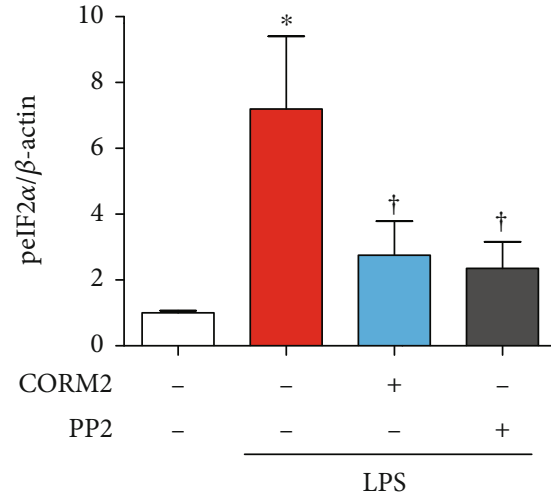

(c)

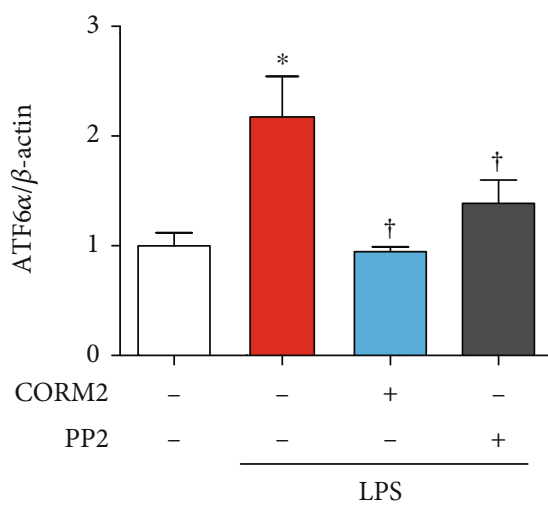

(e)

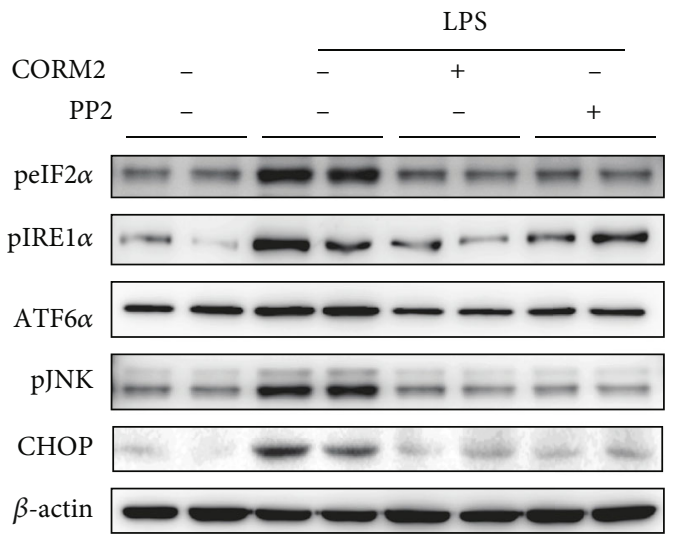

(b)

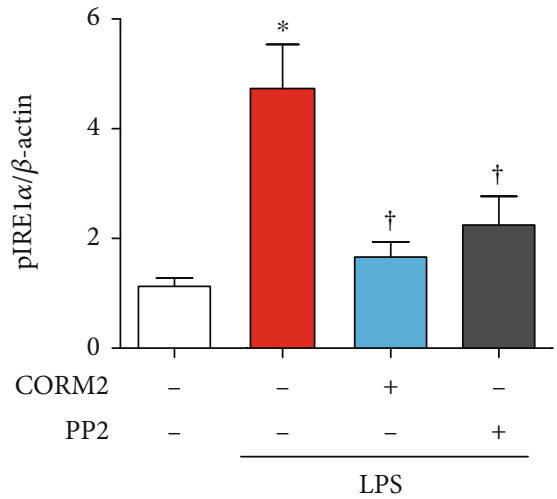

(d)

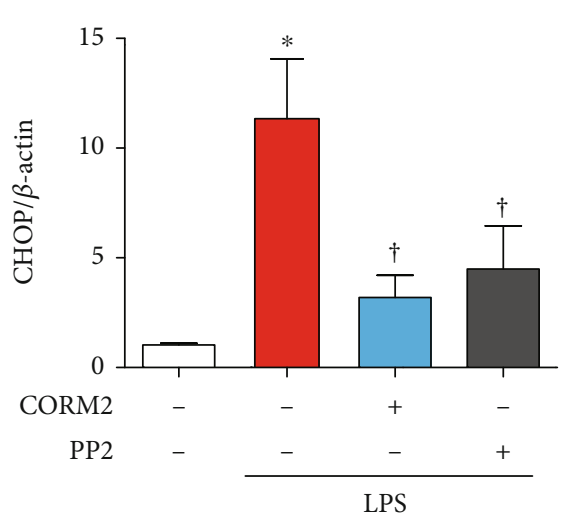

(f)

Figure 3: Continued. 


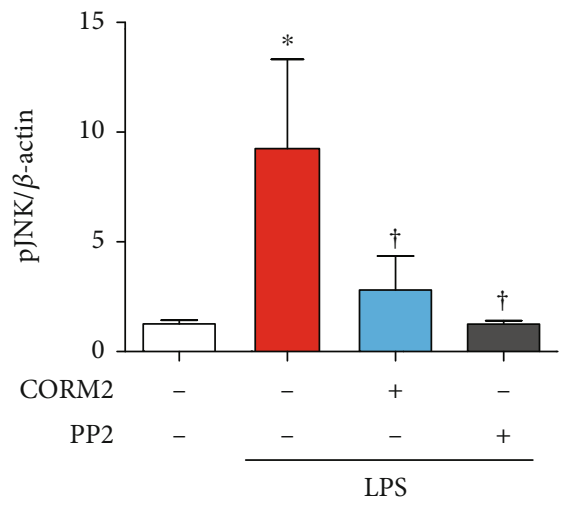

(g)

FIGURE 3: CORM2 inhibits kidney ER stress in LPS-induced AKI mice. (a) The mRNA levels of sXBP1, ER-degradation-enhancing alphamannosidase-like protein-1 (Edem1), and $78 \mathrm{kDa}$ glucose-regulated protein (GRP78) were assessed in the kidney using real-time RT-PCR. (b) Western blotting was employed to determine the protein expression of peIF $2 \alpha$, pIRE1 $\alpha$, ATF6 $\alpha$, pJNK, and CHOP in the kidney, and (c-g) ImageJ software was used to determine the band intensities. Data are presented as means \pm SE, control $(n=8)$, LPS $(n=7-8)$, LPS + CORM2 $(n=8)$, and LPS+PP2 $(n=8) ;{ }^{*} p<0.05$ vs. control and ${ }^{\dagger} p<0.05$ vs. LPS.

3.3. CORM2 Inhibits LPS-Induced Kidney ER Stress. ER stress has been reported as a hallmark of AKI [17, 18]. Thus, we have investigated the effect of CORM2 on ER stress. LPS treatment significantly increased the mRNA levels of ER stress markers including sXBP1, Edem1, and GRP78 in the kidney of AKI mice (Figure 3(a)). These were all considerably reduced by CORM2 or PP2 (Figure 3(a)). Consistently, the protein expression levels of peIF $2 \alpha$, pIRE1 $\alpha$, ATF $6 \alpha$, pJNK, and $\mathrm{CHOP}$ were significantly increased in AKI mice (Figures 3(b)-3(g)). As expected, these changes were significantly suppressed by CORM2 or PP2 (Figures 3(b)-3(g)).

3.4. CORM2 Inhibits LPS-Induced SFK Activation. As shown in Figure 4(a), the mRNA levels of SFKs such as Fyn and cSrc were significantly increased by LPS while CORM2 effectively inhibited these effects. The protein expression levels of pFyn, Fyn, pSrc, and Src were markedly increased by LPS treatment (Figures 4(b) and 4(c)) and were decreased by pretreatment with CORM2 in AKI mice (Figures 4(b) and $4(\mathrm{c})$ ). In addition, immunostaining of $\mathrm{pSrc}$ and $\mathrm{pFyn}$ was markedly detectable in the kidney of LPS-induced AKI mice (Figure 4(d)), and their expression levels were decreased by CORM2 treatment (Figure 4(d)). These data show that CORM2 inhibits not only pFyn and p-c-Src but also total Fyn and c-Src in the kidney of LPS-induced AKI mice.

3.5. CORM2 Reduces LPS-Induced ER Stress through Inhibition of Fyn. $\mathrm{CO}$ attenuates ER stress $[35,36]$, while Fyn contributes to ER stress [24]. Since the importance of tubular epithelial cells in AKI pathophysiology is established [44], the mProx cells have been utilized to validate the protective mechanisms involved in CORM2. We have, first, confirmed the cytotoxic effects of LPS on mProx cells using MTT assays. There was no significant cytotoxic effect up to $1 \mu \mathrm{g} / \mathrm{ml}$ LPS (Supplementary Fig. 2A). Also, there were no significant cytotoxic effects of CORM2 at different concentrations in LPS-treated cells (Supplementary Fig. 2B). Based on these observations, we have chosen the doses of CORM2 $(20 \mu \mathrm{M})$ and LPS $(100 \mathrm{nM})$ for the studies with mProx cells.

Time-dependent treatment with LPS increased the mRNA expression levels of SFK (such as Fyn and c-Src) at 3 and $6 \mathrm{~h}$ (Figure $5(\mathrm{a})$ ), and also, the mRNAs of ER stressresponsive genes (such as sXBP1, Edem, and GRP78) were significantly increased at 6,12, and $24 \mathrm{~h}$ (Figure 5(c)) in mProx cells. Also, time-dependent treatment with LPS significantly increased the mRNAs of proinflammatory genes such a TNF $\alpha$, MCP1, iNOS, and ICAM1 (Supplementary Fig. 3B) and decreased antioxidant enzymes including NRF2 and NQO1 (Supplementary Fig. 3D) in mProx cells. Pretreatment with CORM2 at different doses $(0,5,10$, and $20 \mu \mathrm{M})$ attenuated LPS-induced upregulation of the mRNAs of cSrc and Fyn (Figure 5(b)). LPS increased pFyn and Fyn protein expression at different times (Figure 5(g)). Furthermore, pretreatment with CORM2 at different doses $(0,5,10$, and 20 $\mu \mathrm{M})$ attenuated LPS-induced upregulation of the protein expression of Fyn, pIRE1 $\alpha$, and pJNK (Figure 5(h)).

Pretreatment with CORM2 or PP2 for $2 \mathrm{~h}$ attenuated LPS-induced upregulation of the mRNA expression of sXBP1, Edem, GRP78 (Figure 5(d)), and CHOP (Supplementary Fig. 4A) as well as the expression levels of Fyn, pIRE1 $\alpha$, and pJNK proteins (Figure 5(i)) in mProx cells. As expected, pretreatment with iCORM2 did not inhibit LPSinduced ER stress (Supplementary Fig. 4B-C), supporting the effect of CO on ER stress. LPS significantly increased the mRNA expression levels of Fyn and c-Src in the respective control siRNA groups, and this effect was significantly decreased by CORM2 (Figures 5(e) and 5(f)). However, LPS failed to increase Fyn and c-Src expression under Fyn siRNA (Figure 5(e)) and c-Src siRNA (Figure 5(f)), respectively, indicating the specificity of transfection in the mProx cells. Importantly, LPS significantly increased the mRNA expression levels of sXBP1, Edem, and GRP78 in the respective control siRNAs, effects that were significantly suppressed by CORM2 (Figures 5(e) and 5(f)). Interestingly, LPS failed to increase the mRNA expression levels of sXBP1, Edem, 


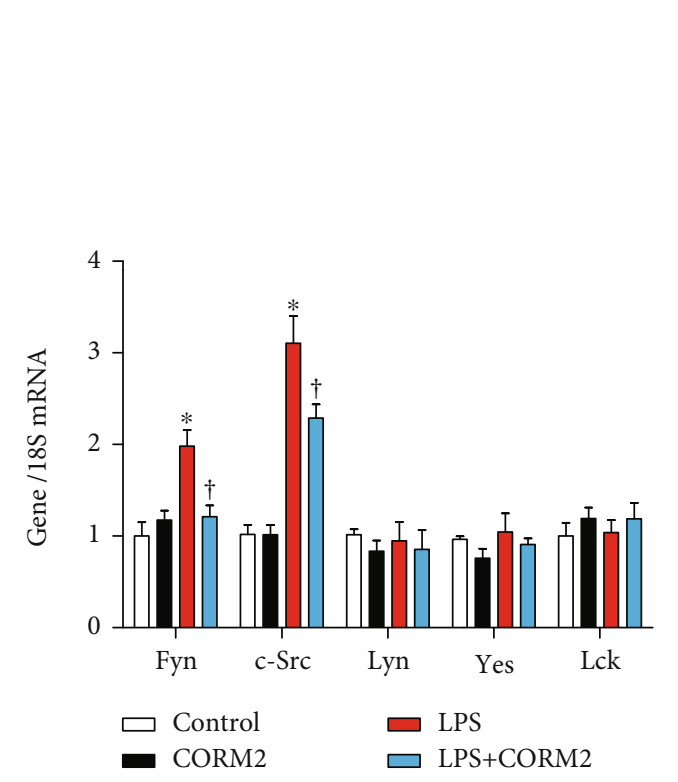

(a)

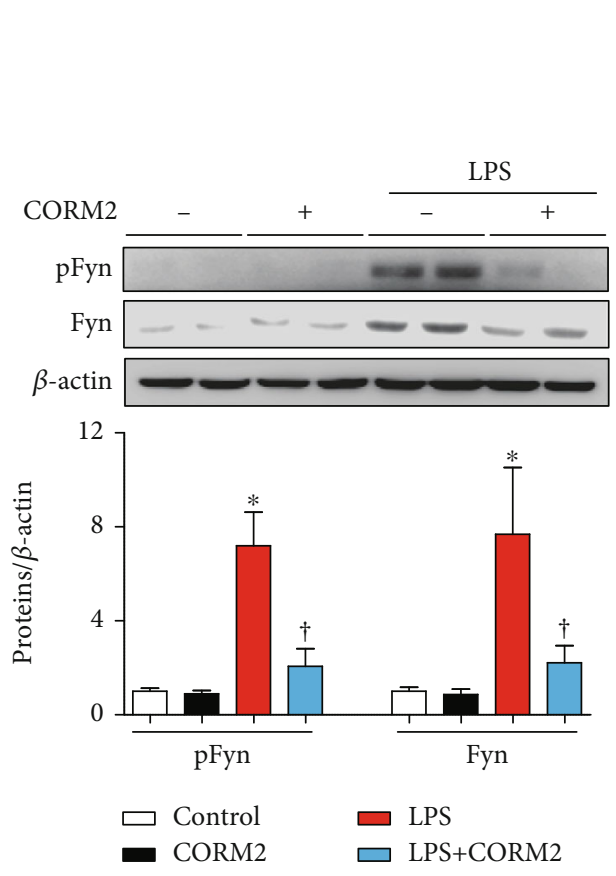

(c)
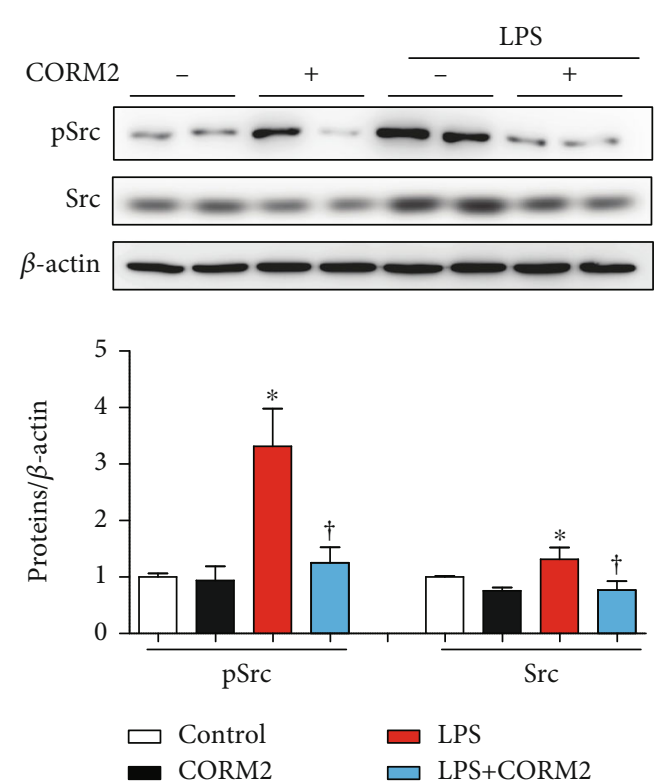

(b)

DAPI
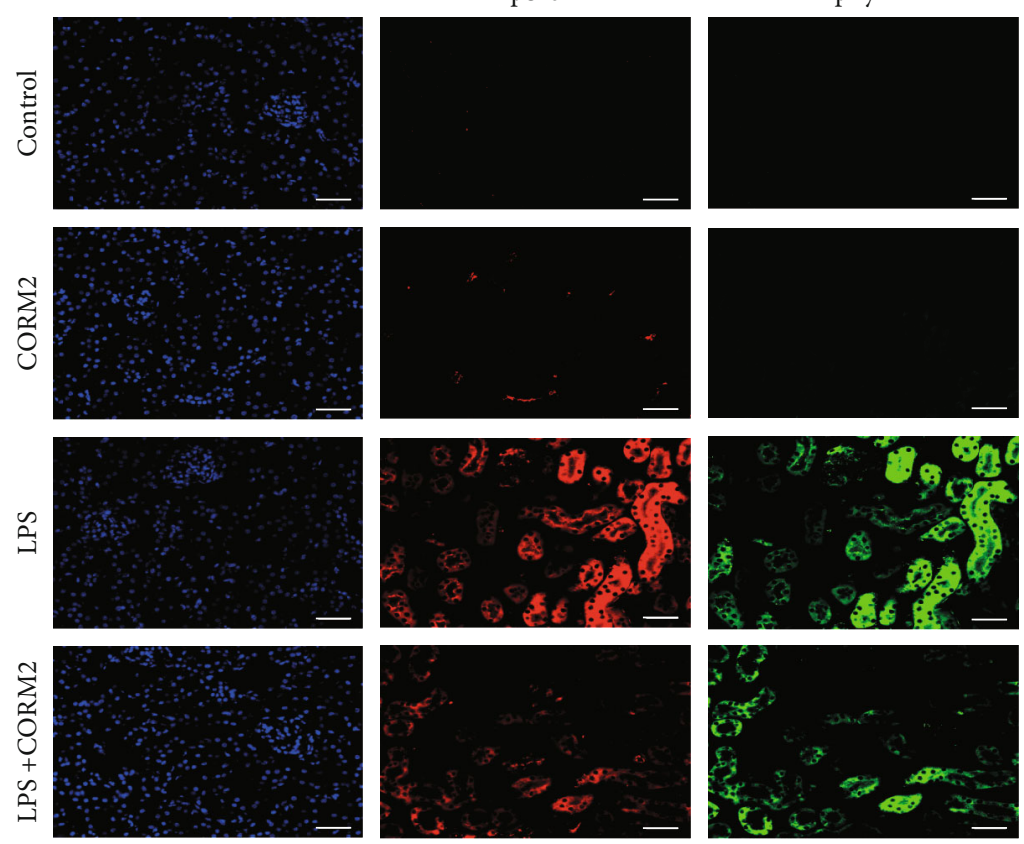

(d)

FIgURE 4: CORM2 inhibits SFK activation in LPS-induced AKI mice. (a) The mRNA levels of SFKs including Fyn, c-Src, Lyn, Yes, and Lck were determined in the kidney using real-time RT-PCR. (b, c) Western blotting analysis of phosphorylated or total Src and Fyn kinase in the kidney was performed. ImageJ software was used to detect the band intensities, and the levels of the proteins were normalized to $\beta$-actin. (d) Paraffin sections of the kidney were incubated with phospho-Fyn (red) and phospho-Src (green) antibodies and 4',6-diamidino-2phenylindole (DAPI; blue). Magnification: 100x; scale bar: $50 \mu \mathrm{m}$. Data in the graph are presented as means \pm SE, control ( $n=8$ ), CORM2 $(n=8)$, LPS $(n=7-8)$, and LPS+CORM2 $(n=7-8) ;{ }^{*} p<0.05$ vs. control, ${ }^{\dagger} p<0.05$ vs. LPS.

and GRP78 under Fyn siRNA (Figure 5(e)), but not c-Src siRNA (Figure 5(f)). In addition, LPS failed to increase the protein expression of ER stress response proteins such as pIRE $1 \alpha$ and pJNK under Fyn siRNA (Figure 5(j)), indicating the potential role of Fyn in the ER stress response in AKI. To verify the influence of CORM2 on ER stress-mediated cell death, we performed TUNEL assays. LPS significantly increased the number of TUNEL-positive mProx cells, an effect that was effectively inhibited by CORM2, NAC, 4PBA, and PP2 (Figure 5(k)).

3.6. CORM2 Decreases LPS-Induced Fyn Activation through Inhibition of ROS. Fyn is induced by ROS through activation of NADPH oxidase [45], while CO is known to inhibit ROS 


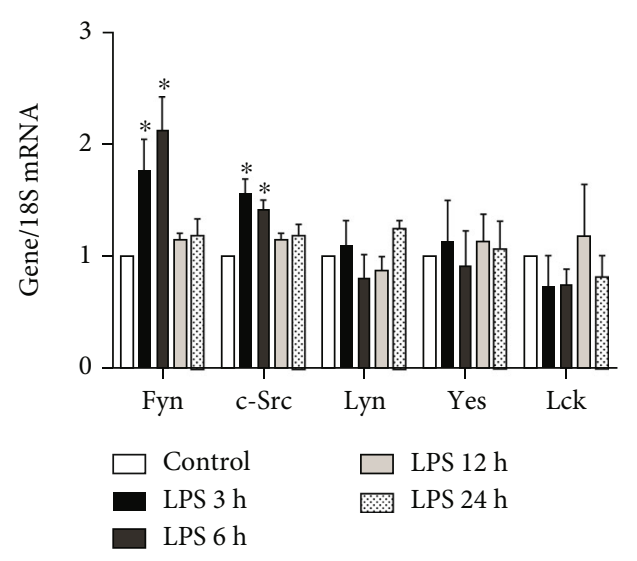

(a)

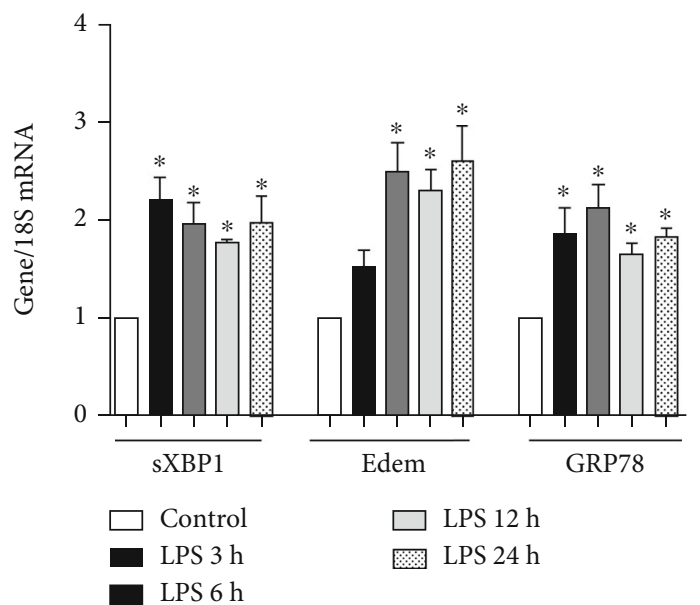

(c)

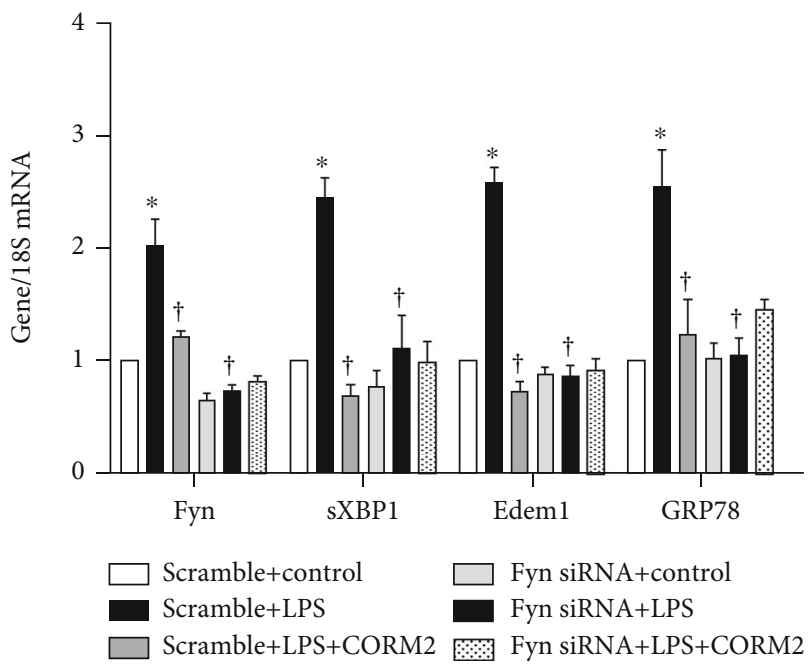

(e)
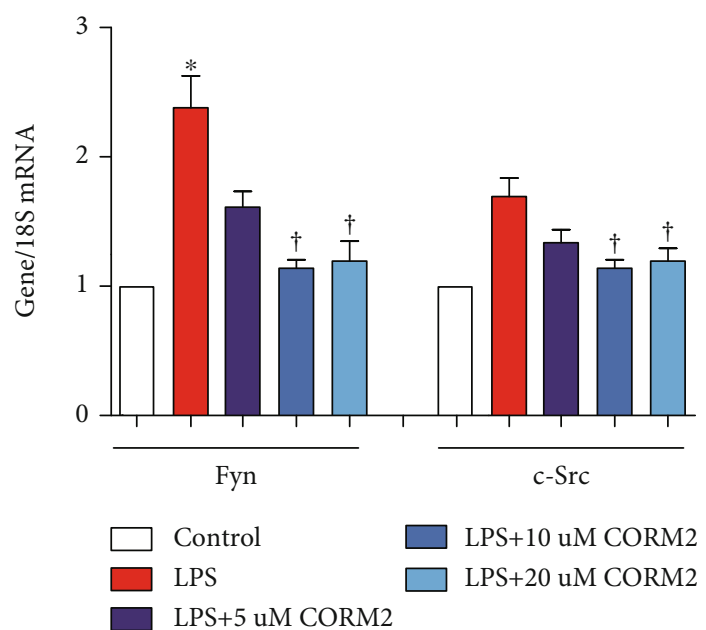

(b)

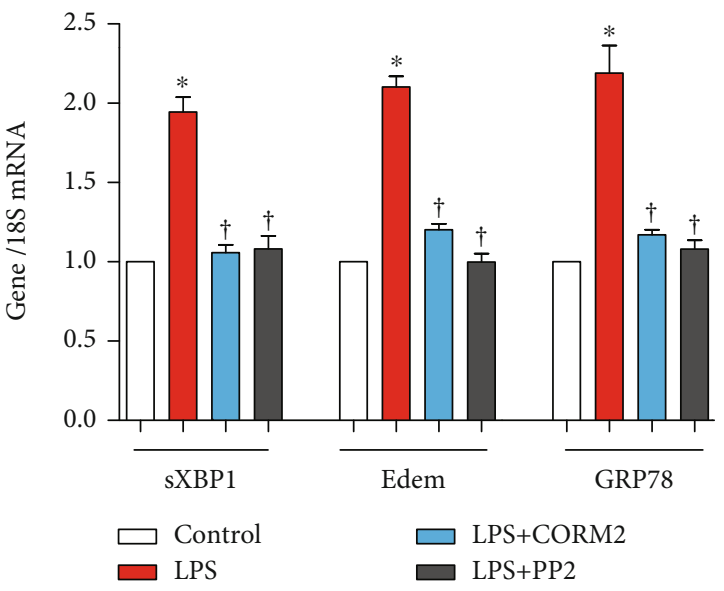

(d)

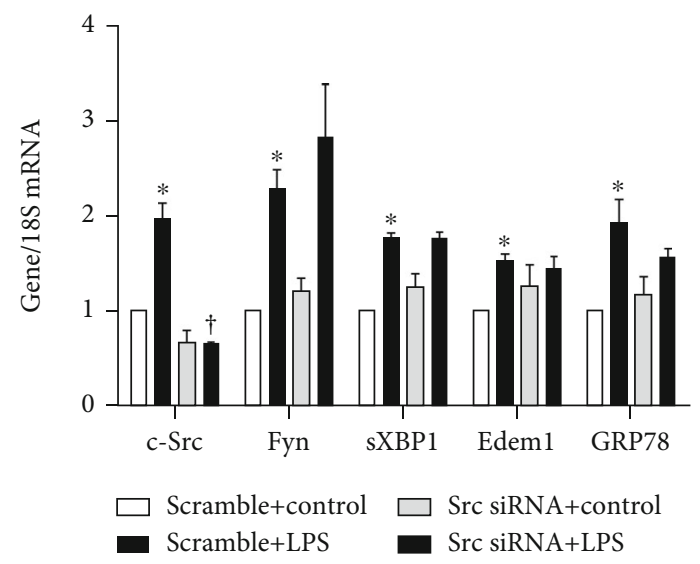

(f)

Figure 5: Continued. 


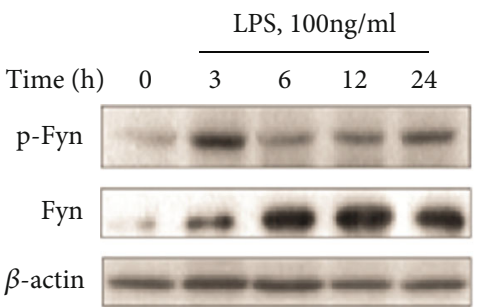

(g)

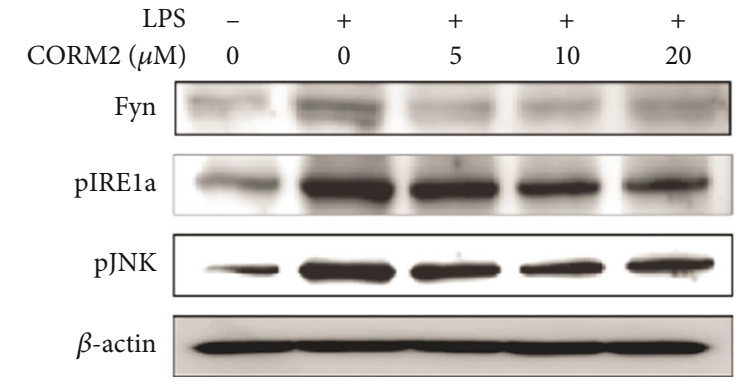

(h)
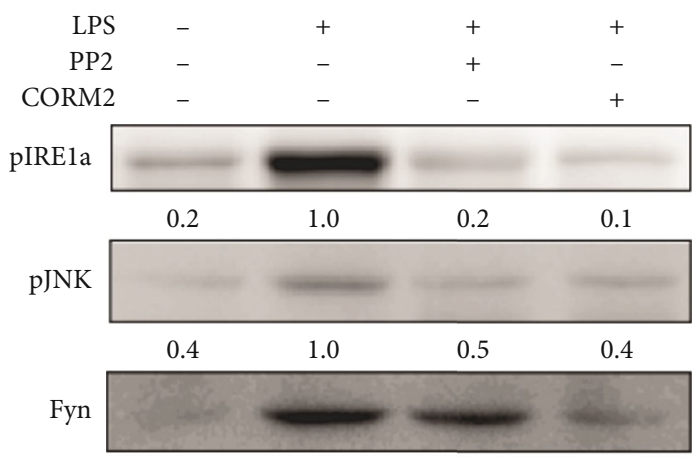

0.1

1.0

0.9

0.3

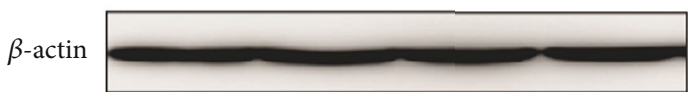

(i)
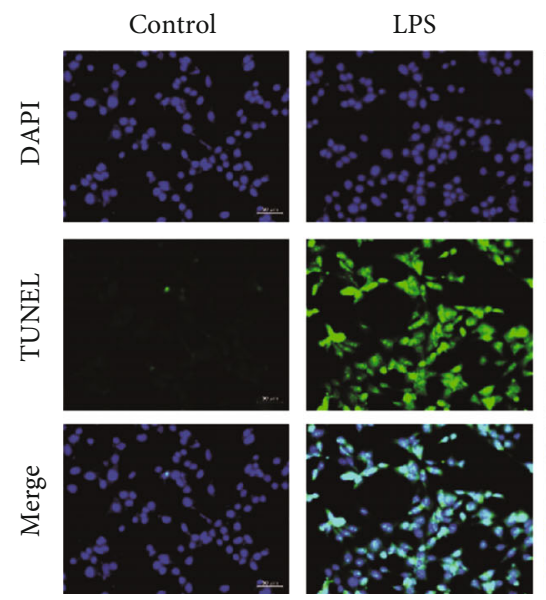

LPS+CORM2

LPS+NAC
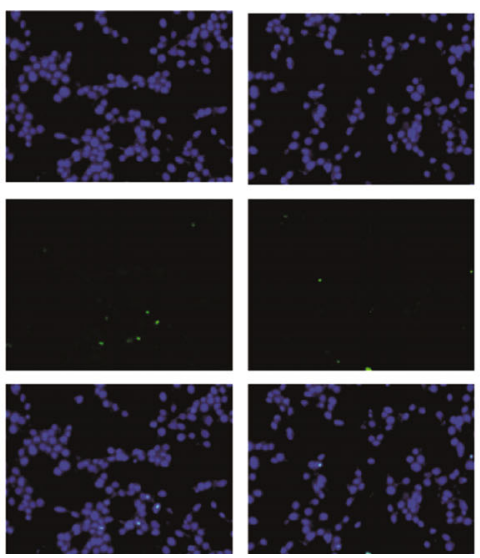

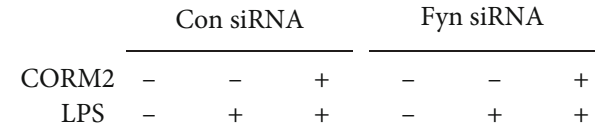

pIRE1a

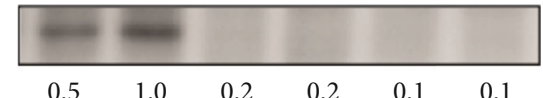

pJNK

$\begin{array}{llllll}0.4 & 1.0 & 0.1 & 0.2 & 0.1 & 0.4\end{array}$

Fyn

$\beta$-actin

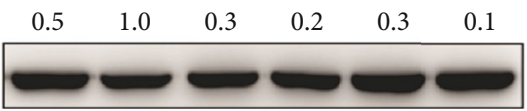

(j)

LPS+4-PBA

LPS+PP2
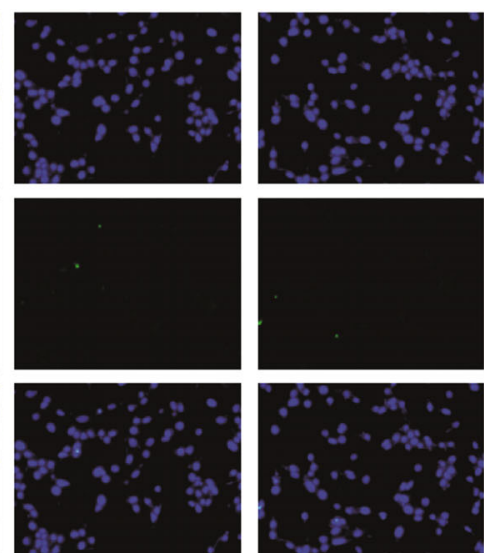

(k)

Figure 5: CORM2 inhibits ER stress through suppression of Fyn in LPS-treated mProx cells. (a, c) Cells were stimulated with LPS (100 ng/ml) in a time-dependent manner $(0,3,6,12$, and $24 \mathrm{~h}$ ). (a) SFK such as Fyn, c-Src, Lyn, Yes, and Lck mRNA levels were measured in the cells. (b, h) Cells were pretreated with CORM2 in a concentration-dependent manner $(0,5,10$, and $20 \mu \mathrm{M})$ for $2 \mathrm{~h}$ and then incubated with LPS (100 $\mathrm{ng} / \mathrm{ml}$ ) for $6 \mathrm{~h}$ or $18 \mathrm{~h}$. (b) The mRNA levels of Fyn and c-Src were measured at $6 \mathrm{~h}$. (c) mRNAs of sXBP1, Edem, and GRP78 were measured. $(\mathrm{d}, \mathrm{i})$ Cells were pretreated with CORM2 $(20 \mu \mathrm{M})$ or PP2 $(10 \mu \mathrm{M})$ for $2 \mathrm{~h}$ and then stimulated with LPS $(100 \mathrm{ng} / \mathrm{ml})$ for $6 \mathrm{~h}$ or $24 \mathrm{~h}$. (d) mRNAs of sXBP1, Edem, and GRP78 were measured. $(e, f, j)$ Cells were transfected with control siRNA and Fyn or c-Src siRNA. Then, they were pretreated with or without CORM2 and incubated with LPS $(100 \mathrm{ng} / \mathrm{ml})$ for $6 \mathrm{~h}$ or $18 \mathrm{~h}$. (e) Fyn siRNA (LPS, $6 \mathrm{~h}$ ): mRNAs of Fyn, sXBP1, Edem, and GRP78 were measured. (f) c-Src siRNA (LPS, 6 h): mRNAs of c-Src, Fyn, sXBP1, Edem, and GRP78 were measured. (g) Cells were treated with LPS $(100 \mathrm{ng} / \mathrm{ml})$ in a time-dependent manner $(0,3,6,12$, and $24 \mathrm{~h})$, and protein expression of pFyn and Fyn was measured. (h) Protein expression of Fyn, pIRE1 $\alpha$, and pJNK at 18 h. (i) Protein expression of Fyn, pIRE1 $\alpha$, and pJNK at $18 \mathrm{~h}$. (j) Fyn siRNA (LPS, $18 \mathrm{~h}$ ): protein expression of Fyn, pIRE1 $\alpha$, and pJNK. (k) Cells were pretreated with CORM2 (20 $\mu \mathrm{M})$ or NAC (5 mM) or 4 PBA $(1 \mathrm{mM})$ or PP2 $(10 \mu \mathrm{M})$ for $2 \mathrm{~h}$ and then incubated with LPS $(100 \mathrm{ng} / \mathrm{ml}) 18 \mathrm{~h}$ followed by TUNEL assays. Magnification: $200 \mathrm{x}$; scale bar: $50 \mu \mathrm{m}$. All mRNAs were analyzed using real-time RT-PCR, and the proteins were measured using Western blotting analysis. ImageJ software was utilized to detect the band intensities, and the levels of the proteins were normalized to $\beta$-actin. Representative protein bands are shown. Data are presented as the mean \pm SE, $n=4$; $^{*} p<0.05$ vs. control, ${ }^{\dagger} p<0.05$ vs. LPS. 


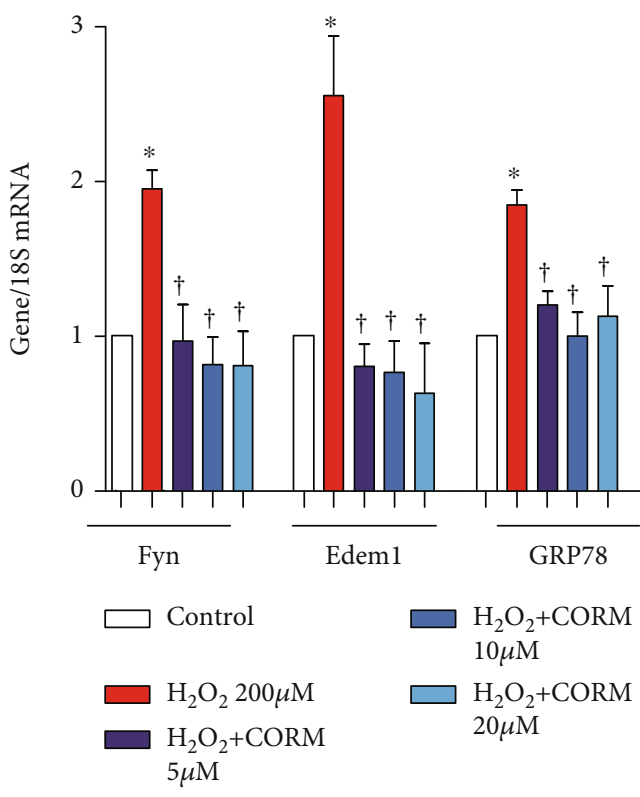

(a)
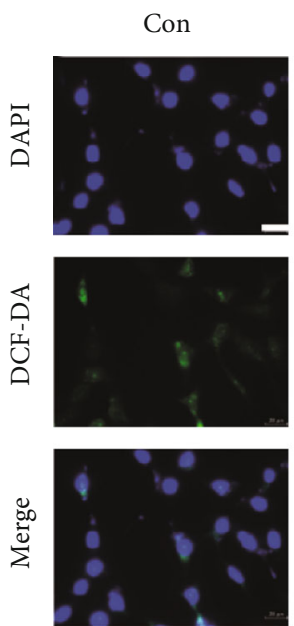

$\mathrm{H}_{2} \mathrm{O}_{2}$
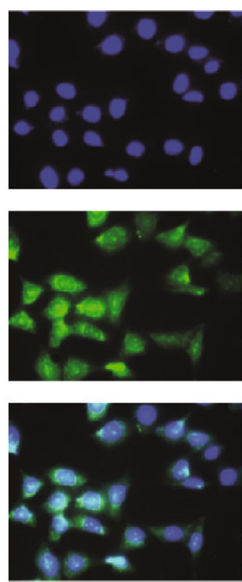

$\mathrm{H}_{2} \mathrm{O}_{2}+\mathrm{CORM} 2$
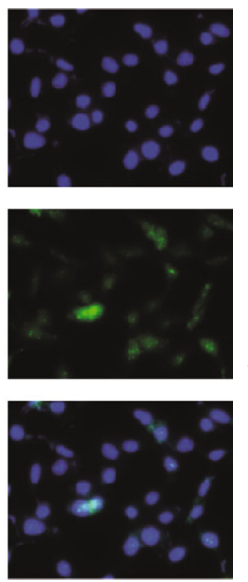

(c)

$\begin{array}{rrrrrr}\mathrm{H}_{2} \mathrm{O}_{2} & - & + & + & + & + \\ \text { CORM2 } & 0 & 0 & 5 & 10 & 20\end{array}$

Fyn

pIRE1a

pJNK

$\beta$-actin
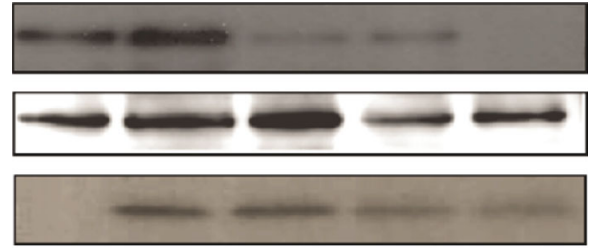

$\beta$-actin

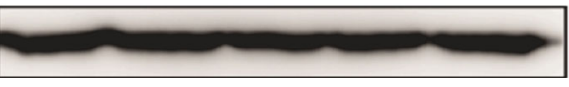

(b)

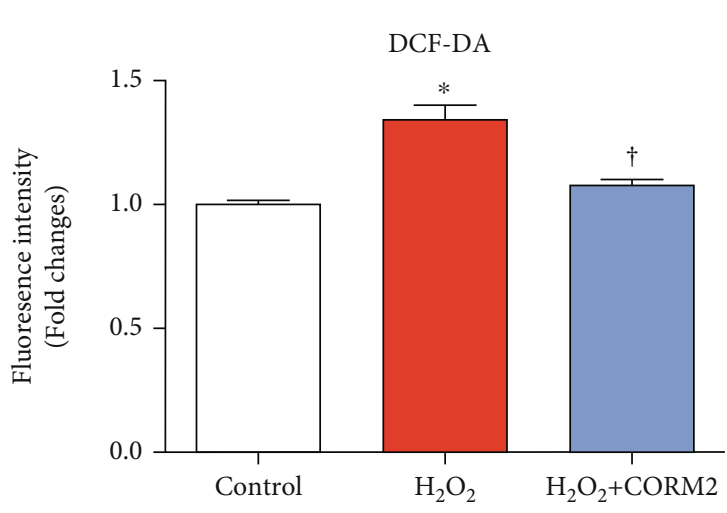

Figure 6: Continued. 


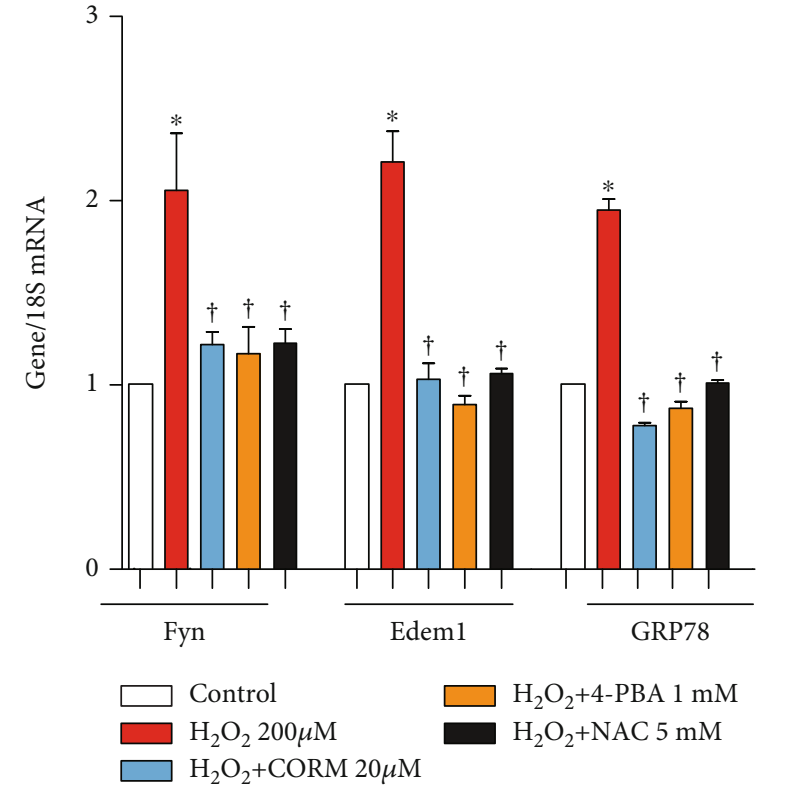

(d)

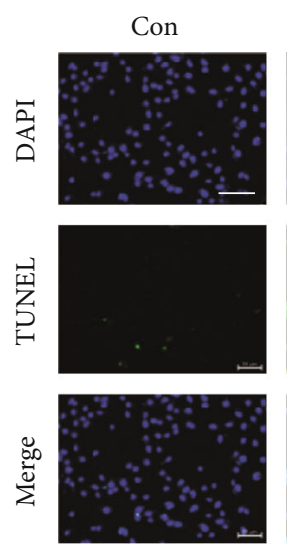

$\mathrm{H}_{2} \mathrm{O}_{2}$
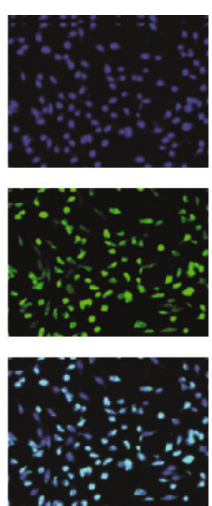

$\mathrm{H}_{2} \mathrm{O}_{2}+$ CORM2
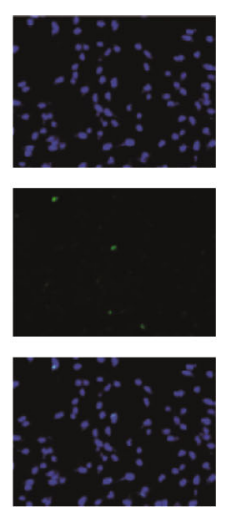

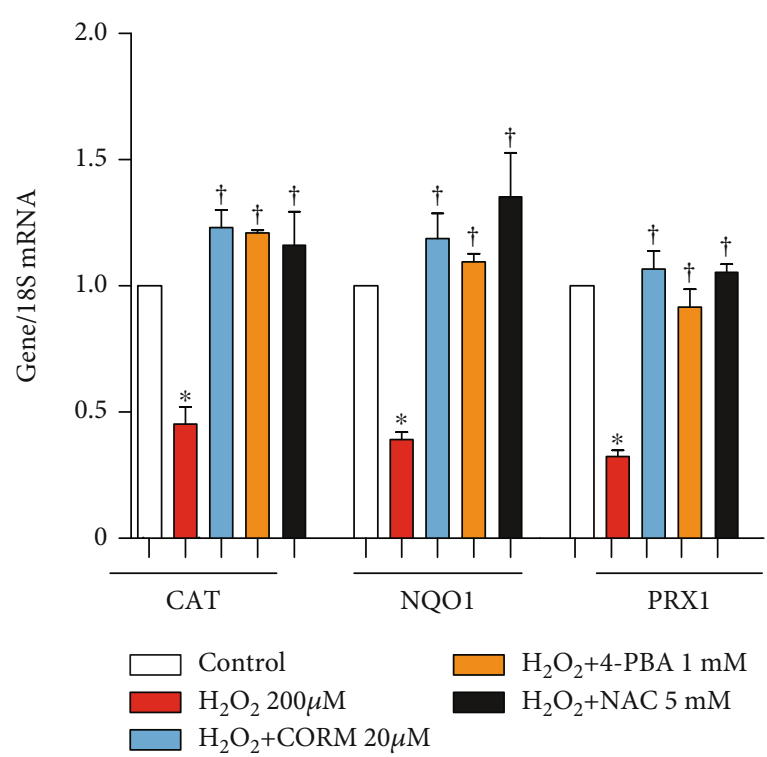

(e)
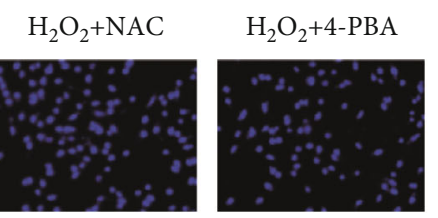

$\mathrm{H}_{2} \mathrm{O}_{2}+\mathrm{PP} 2$
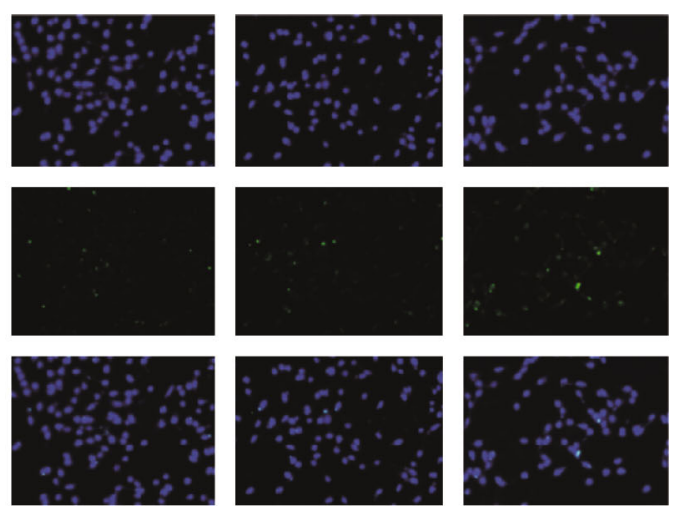

(f)

FIGURE 6: CORM2 inhibits Fyn activation through suppression of ROS in $\mathrm{H}_{2} \mathrm{O}_{2}$-treated mProx cells. (a, b) Cells were pretreated with CORM2 in a concentration-dependent manner $(0,5,10$, and $20 \mu \mathrm{M})$ for $2 \mathrm{~h}$ and then stimulated with $\mathrm{H}_{2} \mathrm{O}_{2}(200 \mu \mathrm{M})$ for $6 \mathrm{~h}$ or $18 \mathrm{~h}$. (a) mRNAs of Fyn, Edem, and GRP78 were measured at 6 h. (b) Proteins of Fyn, pIRE1 $\alpha$, and pJNK were measured at $18 \mathrm{~h}$. (c) The cells were pretreated with $20 \mu \mathrm{M}$ CORM2 for $2 \mathrm{~h}$ and then stimulated with $200 \mu \mathrm{M} \mathrm{H}_{2} \mathrm{O}_{2}$ for $1 \mathrm{~h}$. Then, cells were incubated with DCF-DA for 30 min for measuring ROS within the cells. Fold changes of fluorescence intensity were measured from five random values from 3 independent experiments. (d-f) Cells were pretreated with CORM2 $(20 \mu \mathrm{M})$, NAC $(5 \mathrm{mM})$, 4-PBA $(1 \mathrm{mM})$, or PP2 $(10 \mu \mathrm{M})$ for $2 \mathrm{~h}$ and then stimulated with $\mathrm{H}_{2} \mathrm{O}_{2}$ $(200 \mu \mathrm{M})$ for $6 \mathrm{~h}$ or $18 \mathrm{~h}$. (d) mRNAs of Fyn, Edem, and GRP78 were measured at $6 \mathrm{~h}$. (e) mRNAs of CAT, NQO1, and PRX1 were measured at $6 \mathrm{~h}$. (f) TUNEL assay at $18 \mathrm{~h}$. Magnification: 200x; scale bar: $50 \mu \mathrm{m}$. All mRNAs were measured using real-time RT-PCR, and the proteins were measured using Western blotting analysis. Representative protein bands are shown. Data are presented as the mean $\pm \mathrm{SE}$ , $n=4 ;{ }^{*} p<0.05$ vs. control, ${ }^{\dagger} p<0.05$ vs. $\mathrm{H}_{2} \mathrm{O}_{2}$.

by conformational changes of NADPH oxidase [30-32]. In addition, $\mathrm{CO}$ inhibits $\mathrm{H}_{2} \mathrm{O}_{2}$-induced oxidative stress [33]. CORM2 or PP2 significantly reduced LPS-induced plasma LPO (Figure 2(a)), nitrotyrosine accumulation (Figure 2(b)), ROS levels (Figure 2(c)), and NOX2 and NOX4 expression (Figure 2(d)) in AKI mice. This evidence and our results suggest that CORM2 may suppress Fyn through inhibition of ROS.

We have checked the cytotoxic effect of $\mathrm{H}_{2} \mathrm{O}_{2}$ on mProx cells using MTT assays. There was no significant cytotoxic effect of $\mathrm{H}_{2} \mathrm{O}_{2}$ up to $200 \mu \mathrm{M}$ on mProx cells at the 6 and 24 h time points (Supplementary Fig. 5A-B). $\mathrm{H}_{2} \mathrm{O}_{2}$ at $400 \mu \mathrm{M}$ showed a cytotoxic effect at $24 \mathrm{~h}$ but not at $6 \mathrm{~h}$. Also, $\mathrm{H}_{2} \mathrm{O}_{2}$ significantly increased the mRNA expression levels of Fyn, c-Src, Edem, and GRP78 in mProx cells in a time- and dose-dependent manner (Supplementary Fig. 5C-D). Based on these results, we decided on the time and dose for $\mathrm{H}_{2} \mathrm{O}_{2}$ treatment of the cells.

To confirm the role of ROS on Fyn, we pretreated the mProx cells with CORM2 at different doses (0, 5, 10, and $20 \mu \mathrm{M})$. Various doses of CORM2 significantly reduced the $\mathrm{H}_{2} \mathrm{O}_{2}$-induced mRNA expression levels of Fyn, Edem, and 
GRP78 (Figure 6(a)) and the protein expression levels of Fyn, pIRE $1 \alpha$, and pJNK (Figure 6(b)). Also, $\mathrm{H}_{2} \mathrm{O}_{2}$-induced pFyn expression was inhibited by CORM2 at $1 \mathrm{~h}$ (Supplementary Fig. 5E). Interestingly, CORM2 effectively inhibited $\mathrm{H}_{2} \mathrm{O}_{2}$-induced ROS production in the cells (Figure 6(c)). Pretreatment with CORM2, 4-phenylbutyric acid (4-PBA, an ER stress inhibitor), or N-acetylcysteine (NAC, an antioxidant) significantly decreased the $\mathrm{H}_{2} \mathrm{O}_{2}$-induced upregulation of the mRNA expression levels of Fyn, Edem, and GRP78 (Figure 6(d)). Also, pretreatment with CORM2, 4PBA, or NAC significantly decreased the $\mathrm{H}_{2} \mathrm{O}_{2}$-induced upregulation of the mRNA expression of catalase (CAT), NQO1, and PRX1 (Figure 6(e)). Consistently, $\mathrm{H}_{2} \mathrm{O}_{2}$ significantly increased the number of TUNEL-positive mProx cells, and this was effectively inhibited by CORM2, NAC, 4-PBA, and PP2 (Figure 6(f)).

\section{Discussion}

The current data demonstrate that the treatment of CORM2 exerts a protective effect against LPS-induced AKI by reducing ROS-Fyn-mediated ER stress.

Since the LPS model mimics various aspects of sepsis in humans [46], we have used LPS-induced AKI as an AKI mouse model instead of some other models [38, 47-51]. The protective effects of CORM2 on LPS-induced AKI are coherent with earlier findings [38, 47-51]. CO/CORMs protect against $\mathrm{AKI}$ by inhibiting inflammation, oxidative injury, and cellular apoptosis [38, 47-51]. Considering the protective effects of CORM2 on AKI, we further dissected the mechanisms, focusing on Fyn-ER stress.

$\mathrm{CO}$ reduces ER stress in diverse cell types [35, 36]. Considering that ER stress is associated with kidney tubular epithelial cell apoptosis and injury [7] and that LPS mediates ER stress leading to AKI [43], we have measured peIF2 $\alpha$, pIRE1 $\alpha, \mathrm{ATF} 6 \alpha$, pJNK, and CHOP expression in kidney tissues. Under our experimental conditions, LPS-induced expression of peIF $2 \alpha$, pIRE $1 \alpha$, ATF $6 \alpha$, pJNK, and CHOP was efficiently hindered by CORM2, suggesting a protective effect of CORM2 on ER stress-associated AKI.

Although Fyn is known to be an important regulator in cancer biology [52], recent studies have indicated the involvement of SFKs, including Fyn, in the pathogenesis of progressive CKD [22, 23]. Genetic or pharmacological inhibition of Fyn attenuates kidney fibrosis by inhibition of phospho-STAT3 in UUO mice [23]. Fyn overexpression activates mammalian target of rapamycin complex 1 (mTORC1) through inhibition of the LKB1-AMPK pathway, leading to skeletal muscle atrophy [53]. Fyn promotes ER stress and consecutive activation of the IRE1 $\alpha$-JNK pathway, driving cell death in skeletal muscle [24]. Fyn activates mTORC1 [53] and IRE1 $\alpha$-JNK [24] pathways. While mTOR is associated with ER stress in kidney tubular cells [55], Fyn has been suggested as a potential therapeutic target in AKI [54]. Thus, it is suggested that suppression of Fyn may attenuate AKI through inhibition of ER stress. Accordingly, the present study showed that pharmacologic or genetic inhibition of Fyn suppressed ER stress responses in the kidney of LPStreated AKI mice as well as in mProx cells.

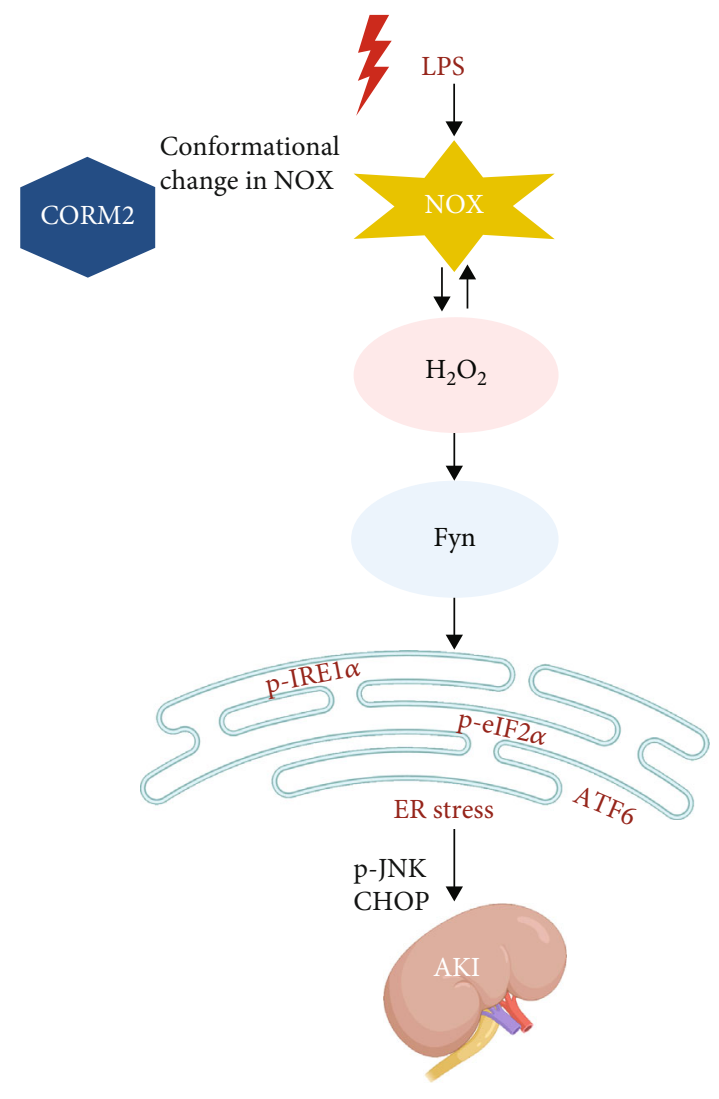

FIGURE 7: Suggested schematic diagram for the effect of CO on ROSFyn-ER stress activation in LPS-induced AKI. LPS mediates ROS leading to Fyn-ER stress signaling, which activates apoptosis signaling (such as CHOP and pJNK) in AKI. CO attenuates ER stress through suppression of Fyn activation in AKI. LPS-induced ROS is connected to activation of Fyn, while CO is known to reduce ROS levels. Thus, $\mathrm{CO}$ may become an alternative treatment option against Fyn-mediated ER stress in AKI.

ROS is associated with ER stress $[9,10]$. The inhibition of ROS by NAC effectively attenuated ER stress responses in IRI-induced AKI in mice [56]. NADPH oxidase (NOX) enzyme complexes are endogenous sources of ROS such as $\mathrm{O}_{2}{ }^{-}$and $\mathrm{H}_{2} \mathrm{O}_{2}$. Inhibition of NOX1 leads to attenuation of elevated ROS levels in in vitro models of atopic dermatitis (AD) and psoriasis (PSO) in keratinocytes [57]. CO is known to inhibit ROS by conformational changes in NOX [30-32]. CO-releasing molecules such as CORM2 and CORM-401 effectively inhibit $\mathrm{H}_{2} \mathrm{O}_{2}$-induced $\mathrm{ROS}$ production in the murine intestinal epithelial MODE-K cells [58]. Consistent with this, CORM2 significantly reduced $\mathrm{H}_{2} \mathrm{O}_{2}$-induced ROS production in mProx cells under our experimental conditions. Yet, CORM3 had no direct inhibitory effects on the $\mathrm{H}_{2} \mathrm{O}_{2}$ concentration in a test tube [33]. Since generation of ROS is linked with ER stress, CO may perform a vital role in the reduction in ROS-mediated ER stress during AKI. In the current study, CORM2 treatment not only efficiently reduced oxidative stress but also significantly enhanced antioxidant gene levels in LPS-treated AKI mice. Under oxidative stress conditions, ROS increases SKFs, including Fyn expression [45]. ROS (such as $\mathrm{H}_{2} \mathrm{O}_{2}$ ) directly oxidizes cysteine 488 
of Fyn resulting in increased Fyn kinase activity in human epidermal keratinocytes and murine embryonic fibroblasts and subsequently activates JNK, a downstream target of Fyn [59]. Consistently, in our study, LPS or $\mathrm{H}_{2} \mathrm{O}_{2}$ effectively increased pJNK and other ER stress markers, as well as cellular apoptosis. Interestingly, these effects were all inhibited by CORM2, NAC, 4-PBA, and PP2. CORM2 also suppressed LPS- or $\mathrm{H}_{2} \mathrm{O}_{2}$-induced Fyn and c-Src activation. In addition, LPS failed to increase ER stress responses under Fyn siRNA, but not c-Src siRNA. These data indicate the potential suppressive effect of $\mathrm{CO}$ on the ROS-Fyn-ER stress axis in AKI.

However, there are several unanswered questions such as the following: (a) the delayed treatment of CORM2 on AKI was not studied, (b) the detailed mechanisms involved in the inhibition of $\mathrm{H}_{2} \mathrm{O}_{2}$-mediated Fyn-ER stress signaling by CORM2 have not been explored, and (c) protocol of optimal delivery and dosing and the possible treatment of $\mathrm{CO}$ in human diseases have not been recognized yet. Further, tolllike receptors (TLRs), mainly TLR4, are an important player in inflammation and many other cellular processes in the progression of AKI [60]. Treatment of CORM2 attenuated the levels of TLR2 and TLR4/ROS and reduced inflammation in the lung [61]. Thus, it needs to examine whether CORM2 can attenuate AKI via inhibition of TLRs. In addition, premature senescence estimated by $\beta$-galactosidase and p53/p21 expression in NRK52E cells [62] and M1 macrophage polarization in RAW264.7 macrophages [63] have recently showed to play a role in AKI. Therefore, the effect of CORM2 on LPS-induced senescence and macrophage polarization in AKI needs to be investigated.

In conclusion, our results and existing evidence supports that stress stimuli (such as LPS)-induced oxidative stress mediates Fyn-ER stress signaling and that inhibition of oxidative stress by CORM2 may have a protective effect against AKI (Figure 7). In the present study, LPS significantly induced kidney injury, oxidative stress, ER stress, tubular apoptosis, and inflammation, which were all inhibited by CORM2 in AKI mice and mProx cells. In addition, CORM2 suppressed LPS- or $\mathrm{H}_{2} \mathrm{O}_{2}$-induced Fyn activities in vivo and in vitro. LPS failed to increase ER stress responses under Fyn siRNA, but not c-Src siRNA, indicating the potential role of Fyn in the ER stress response in AKI. These findings suggest that treatment of CORM2 aimed at preventing ROSmediated Fyn-ER stress signaling may become a promising option to treat AKI.

\section{Data Availability}

All data could be found within the manuscript.

\section{Conflicts of Interest}

The authors declare no conflicts of interest.

\section{Authors' Contributions}

MJU and $\mathrm{HH}$ contributed to the conception and design of the experiments. MJU, JJ, and ESP were involved in performing the experiments. MJU contributed to analyzing the data as well as drafting and revising the article. MJU and $\mathrm{HH}$ provided intellectual content of critical importance to the work described. $\mathrm{HH}$ made the final approval of the version to be published.

\section{Acknowledgments}

NOX2 and NOX4 antibodies were a kind gift of Professor Yun Soo Bae, Department of Life Science, College of Natural Sciences, Ewha Womans University, Seoul, Korea. This work was supported by the National Research Foundation (Nos. 2020R1I1A1A01072879 and 2015H1D3A1062189) and the Brain Pool program funded by the Ministry of Science and ICT through the National Research Foundation of Korea (No. 2020H1D3A2A02110924).

\section{Supplementary Materials}

Supplementary Fig. 1: CORM2 improves body weight and kidney to body weight in AKI mice. Supplementary Fig. 2: effect of LPS and CORM2 on the viability of mProx cells. Supplementary Fig. 3: effect of LPS or CORM2 on inflammation and oxidative stress in mice and mProx cells. Supplementary Fig. 4: effect of CORM2 on ER stress signaling in mProx cells. Supplementary Fig. 5: effect of $\mathrm{H}_{2} \mathrm{O}_{2}$ on cell viability and ER stress responses in mProx cells. (Supplementary Materials)

\section{References}

[1] S. Uchino, J. A. Kellum, R. Bellomo et al., "Acute renal failure in critically ill patients: a multinational, multicenter study," JAMA, vol. 294, no. 7, pp. 813-818, 2005.

[2] S. G. Coca, S. Singanamala, and C. R. Parikh, "Chronic kidney disease after acute kidney injury: a systematic review and meta-analysis," Kidney International, vol. 81, no. 5, pp. 442448, 2012.

[3] A. J. Lewington, J. Cerdá, and R. L. Mehta, "Raising awareness of acute kidney injury: a global perspective of a silent killer," Kidney International, vol. 84, no. 3, pp. 457-467, 2013.

[4] A. Zarbock, H. Gomez, and J. A. Kellum, "Sepsis-induced acute kidney injury revisited: pathophysiology, prevention and future therapies," Current Opinion in Critical Care, vol. 20, no. 6, pp. 588-595, 2014.

[5] K. Doi, "Role of kidney injury in sepsis," Journal of Intensive Care, vol. 4, no. 1, 2016.

[6] F. Togel and C. Westenfelder, "Recent advances in the understanding of acute kidney injury," F1000Prime Reports, vol. 6, 2014.

[7] A. Linkermann, G. Chen, G. Dong, U. Kunzendorf, S. Krautwald, and Z. Dong, "Regulated cell death in AKI," Journal of the American Society of Nephrology, vol. 25, no. 12, pp. 2689-2701, 2014.

[8] D. P. Basile, M. D. Anderson, and T. A. Sutton, "Pathophysiology of acute kidney injury," Comprehensive Physiology, vol. 2, no. 2, pp. 1303-1353, 2012.

[9] H. Lin, X. B. Liu, J. J. Yu, F. Hua, and Z. W. Hu, “Antioxidant $\mathrm{N}$-acetylcysteine attenuates hepatocarcinogenesis by inhibiting ROS/ER stress in TLR2 deficient mouse," PLoS One, vol. 8, no. 10, p. e74130, 2013. 
[10] Q. Wang, H. Wang, Y. Jia, H. Pan, and H. Ding, "Luteolin induces apoptosis by ROS/ER stress and mitochondrial dysfunction in gliomablastoma," Cancer Chemotherapy and Pharmacology, vol. 79, no. 5, pp. 1031-1041, 2017.

[11] G. R. Kinsey and M. D. Okusa, "Pathogenesis of acute kidney injury: foundation for clinical practice," American Journal of Kidney Diseases, vol. 58, no. 2, pp. 291-301, 2011.

[12] J. L. Alge and J. M. Arthur, "Biomarkers of AKI: a review of mechanistic relevance and potential therapeutic implications," Clinical Journal of the American Society of Nephrology, vol. 10, no. 1, pp. 147-155, 2015.

[13] M. Calfon, H. Zeng, F. Urano et al., "IRE1 couples endoplasmic reticulum load to secretory capacity by processing the _XBP-1_mRNA," Nature, vol. 415, no. 6867, pp. 92-96, 2002.

[14] S. Kim, Y. Joe, H. J. Kim et al., "Endoplasmic reticulum stress-induced IRE1 $\alpha$ activation mediates cross-talk of GSK-3 $\beta$ and XBP-1 to regulate inflammatory cytokine production," The Journal of Immunology, vol. 194, no. 9, pp. 4498-4506, 2015.

[15] F. Urano, X. Wang, A. Bertolotti et al., "Coupling of stress in the ER to activation of JNK protein kinases by transmembrane protein kinase IRE1," Science, vol. 287, no. 5453, pp. 664-666, 2000.

[16] M. J. Uddin, E. S. Pak, and H. Ha, "Carbon monoxide releasing molecule-2 protects mice against acute kidney injury through inhibition of ER stress," The Korean Journal of Physiology \& Pharmacology, vol. 22, no. 5, pp. 567-575, 2018.

[17] R. E. Carlisle, E. Brimble, K. E. Werner et al., "4-Phenylbutyrate inhibits tunicamycin-induced acute kidney injury via CHOP/GADD153 repression," PLoS One, vol. 9, no. 1, p. e84663, 2014.

[18] X. Gao, L. Fu, M. Xiao et al., "The nephroprotective effect of tauroursodeoxycholic acid on ischaemia/reperfusion-induced acute kidney injury by inhibiting endoplasmic reticulum stress," Basic \& Clinical Pharmacology \& Toxicology, vol. 111, no. 1, pp. 14-23, 2012.

[19] E. Calautti, M. Grossi, C. Mammucari et al., "Fyn tyrosine kinase is a downstream mediator of Rho/PRK2 function in keratinocyte cell-cell adhesion," Journal of Cell Biology, vol. 156, no. 1, pp. 137-148, 2002.

[20] M. W. Appleby, J. A. Gross, M. P. Cooke, S. D. Levin, X. Qian, and R. M. Perlmutter, "Defective T cell receptor signaling in mice lacking the thymic isoform of p59fyn," Cell, vol. 70, no. 5, pp. 751-763, 1992.

[21] K. Sugie, T. Kawakami, Y. Maeda, T. Kawabe, A. Uchida, and J. Yodoi, "Fyn tyrosine kinase associated with Fc epsilon RII/CD23: possible multiple roles in lymphocyte activation," Proceedings of the National Academy of Sciences, vol. 88, no. 20, pp. 9132-9135, 1991.

[22] J. Wang and S. Zhuang, "Src family kinases in chronic kidney disease," American Journal of Physiology-Renal Physiology, vol. 313, no. 3, pp. F721-F728, 2017.

[23] H. Y. Seo, J. H. Jeon, Y. A. Jung et al., "Fyn deficiency attenuates renal fibrosis by inhibition of phospho-STAT3," Kidney International, vol. 90, no. 6, pp. 1285-1297, 2016.

[24] Y. Wang, E. Yamada, H. Zong, and J. E. Pessin, "Fyn activation of mTORC1 stimulates the IRE1alpha-JNK pathway, leading to cell death," Journal of Biological Chemistry, vol. 290, no. 41, pp. 24772-24783, 2015.

[25] K. Nakahira and A. M. Choi, "Carbon monoxide in the treatment of sepsis," American Journal of Physiology-Lung Cellular and Molecular Physiology, vol. 309, no. 12, pp. L1387-L1393, 2015.

[26] M. J. Uddin, C. S. Li, Y. Joe et al., "Carbon monoxide inhibits Tenascin-C mediated inflammation via IL-10 expression in a septic mouse model," Mediators of Inflammation, vol. 2015, Article ID 613249, 14 pages, 2015.

[27] M. Zheng, Q. Zhang, Y. Joe et al., "Carbon monoxide-releasing molecules reverse leptin resistance induced by endoplasmic reticulum stress," American Journal of PhysiologyEndocrinology and Metabolism, vol. 304, no. 7, pp. E780E788, 2013.

[28] M. J. Uddin, S. O. Jeong, M. Zheng et al., "Carbon Monoxide Attenuates Dextran Sulfate Sodium-Induced Colitis via Inhibition of GSK-3 $\beta$ Signaling," Oxidative Medicine and Cellular Longevity, vol. 2013, Article ID 210563, 9 pages, 2013.

[29] Y. Joe, M. Zheng, S. K. Kim et al., "The role of carbon monoxide in metabolic disease," Annals of the New York Academy of Sciences, vol. 1229, no. 1, pp. 156-161, 2011.

[30] G. P. Roberts, H. Youn, and R. L. Kerby, "CO-sensing mechanisms," Microbiology and Molecular Biology Reviews, vol. 68, no. 3, pp. 453-473, 2004.

[31] C. Taille, J. El-Benna, S. Lanone, J. Boczkowski, and R. Motterlini, "Mitochondrial respiratory chain and NAD $(\mathrm{P}) \mathrm{H}$ oxidase are targets for the antiproliferative effect of carbon monoxide in human airway smooth muscle," Journal of Biological Chemistry, vol. 280, no. 27, pp. 25350-25360, 2005.

[32] H. Matsumoto, K. Ishikawa, H. Itabe, and Y. Maruyama, "Carbon monoxide and bilirubin from heme oxygenase-1 suppresses reactive oxygen species generation and plasminogen activator inhibitor-1 induction," Molecular and Cellular Biochemistry, vol. 291, no. 1-2, pp. 21-28, 2006.

[33] Y. Huang, T. Ma, Z. Ye et al., "Carbon monoxide (CO) inhibits hydrogen peroxide $\left(\mathrm{H}_{2} \mathrm{O}_{2}\right)$-induced oxidative stress and the activation of NF- $\kappa \mathrm{B}$ signaling in lens epithelial cells," Experimental Eye Research, vol. 166, pp. 29-39, 2018.

[34] C. W. Lee, C. H. Wu, Y. C. Chiang et al., "Carbon monoxide releasing molecule-2 attenuates_Pseudomonas aeruginosa_ -induced ROS-dependent ICAM-1 expression in human pulmonary alveolar epithelial cells," Redox Biology, vol. 18, pp. 93-103, 2018.

[35] K. M. Kim, H. O. Pae, M. Zheng, R. Park, Y. M. Kim, and H. T. Chung, "Carbon monoxide induces heme oxygenase-1 via activation of protein kinase R-like endoplasmic reticulum kinase and inhibits endothelial cell apoptosis triggered by endoplasmic reticulum stress," Circulation Research, vol. 101, no. 9, pp. 919-927, 2007.

[36] D. S. Kim, L. Song, J. Wang et al., "Carbon monoxide inhibits islet apoptosis via induction of autophagy," Antioxidants \& Redox Signaling, vol. 28, no. 14, pp. 1309-1322, 2018.

[37] L. Wang, J. Y. Lee, J. H. Kwak, Y. He, S. I. Kim, and M. E. Choi, "Protective effects of low-dose carbon monoxide against renal fibrosis induced by unilateral ureteral obstruction," American Journal of Physiology-Renal Physiology, vol. 294, no. 3, pp. F508-F517, 2008.

[38] P. Wang, J. Huang, Y. Li et al., "Exogenous carbon monoxide decreases sepsis-induced acute kidney injury and inhibits NLRP3 inflammasome activation in rats," International Journal of Molecular Sciences, vol. 16, no. 9, pp. 20595-20608, 2015.

[39] A. Nakao, T. Yamada, K. Kohama, N. Yoshie, N. Fujisaki, and J. Kotani, "Application of carbon monoxide for treatment of 
acute kidney injury," Acute Medicine \& Surgery, vol. 1, no. 3, pp. 127-134, 2014.

[40] H. Ha, M. R. Yu, and K. H. Kim, "Melatonin and taurine reduce early glomerulopathy in diabetic rats," Free Radical Biology and Medicine, vol. 26, no. 7-8, pp. 944-950, 1999.

[41] M. Sohn, K. Kim, M. J. Uddin et al., "Delayed treatment with fenofibrate protects against high-fat diet-induced kidney injury in mice: the possible role of AMPK autophagy," American Journal of Physiology-Renal Physiology, vol. 312, no. 2, pp. F323-F334, 2017.

[42] H. Ha, M. R. Yu, Y. J. Choi, M. Kitamura, and H. B. Lee, "Role of high glucose-induced nuclear factor-kappaB activation in monocyte chemoattractant protein-1 expression by mesangial cells," Journal of the American Society of Nephrology, vol. 13, no. 4, pp. 894-902, 2002.

[43] H. Zhang, W. Zhang, F. Jiao, X. Li, L. Wang, and Z. Gong, "The nephroprotective effect of MS-275 on lipopolysaccharide (LPS)-induced acute kidney injury by inhibiting reactive oxygen species (ROS)-oxidative stress and endoplasmic reticulum stress," Medical Science Monitor, vol. 24, pp. 2620-2630, 2018.

[44] S. M. Sancho-Martinez, J. M. Lopez-Novoa, and F. J. LopezHernandez, "Pathophysiological role of different tubular epithelial cell death modes in acute kidney injury," Clinical Kidney Journal, vol. 8, no. 5, pp. 548-559, 2015.

[45] D. Santosa, M. Castoldi, M. Paluschinski, A. Sommerfeld, and D. Haussinger, "Hyperosmotic stress activates the expression of members of the miR-15/107 family and induces downregulation of anti-apoptotic genes in rat liver," Scientific Reports, vol. 5, no. 1, 2015.

[46] K. Doi, A. Leelahavanichkul, P. S. Yuen, and R. A. Star, "Animal models of sepsis and sepsis-induced kidney injury," Journal of Clinical Investigation, vol. 119, no. 10, pp. 2868-2878, 2009.

[47] T. Vera, J. R. Henegar, H. A. Drummond, J. M. Rimoldi, and D. E. Stec, "Protective effect of carbon monoxide-releasing compounds in ischemia-induced acute renal failure," Journal of the American Society of Nephrology, vol. 16, no. 4, pp. 950-958, 2005.

[48] J. S. Neto, A. Nakao, K. Kimizuka et al., "Protection of transplant-induced renal ischemia-reperfusion injury with carbon monoxide," American Journal of Physiology-Renal Physiology, vol. 287, no. 5, pp. F979-F989, 2004.

[49] Y. Tayem, T. R. Johnson, B. E. Mann, C. J. Green, and R. Motterlini, "Protection against cisplatin-induced nephrotoxicity by a carbon monoxide-releasing molecule," American Journal of Physiology-Renal Physiology, vol. 290, no. 4, pp. F789-F794, 2006.

[50] S. Shiohira, T. Yoshida, S. Shirota, K. Tsuchiya, and K. Nitta, "Protective effect of carbon monoxide donor compounds in endotoxin-induced acute renal failure," American Journal of Nephrology, vol. 27, no. 5, pp. 441-446, 2007.

[51] T. Abe, K. Yazawa, M. Fujino et al., "High-pressure carbon monoxide preserves rat kidney grafts from apoptosis and inflammation," Laboratory Investigation, vol. 97, no. 4, pp. 468-477, 2017.

[52] D. Elias and H. J. Ditzel, "Fyn is an important molecule in cancer pathogenesis and drug resistance," Pharmacological Research, vol. 100, pp. 250-254, 2015.

[53] E. Yamada, C. C. Bastie, H. Koga, Y. Wang, A. M. Cuervo, and J. E. Pessin, "Mouse skeletal muscle fiber-type-specific macroautophagy and muscle wasting are regulated by a Fyn/-
STAT3/Vps34 signaling pathway," Cell Reports, vol. 1, no. 5, pp. 557-569, 2012.

[54] M. J. Uddin, D. Dorotea, E. S. Pak, and H. Ha, "Fyn kinase: a potential therapeutic target in acute kidney injury," Biomolecules \& Therapeutics, vol. 28, no. 3, pp. 213-221, 2020.

[55] G. Dong, Y. Liu, L. Zhang, S. Huang, H. F. Ding, and Z. Dong, "mTOR contributes to ER stress and associated apoptosis in renal tubular cells," American Journal of Physiology-Renal Physiology, vol. 308, no. 3, pp. F267-F274, 2015.

[56] Y. Gu, F. Huang, Y. Wang et al., "Connexin32 plays a crucial role in ROS-mediated endoplasmic reticulum stress apoptosis signaling pathway in ischemia reperfusion-induced acute kidney injury," Journal of Translational Medicine, vol. 16, no. 1, p. 117, 2018.

[57] H. Emmert, M. Fonfara, E. Rodriguez, and S. Weidinger, "NADPH oxidase inhibition rescues keratinocytes from elevated oxidative stress in a $2 \mathrm{D}$ atopic dermatitis and psoriasis model," Experimental Dermatology, vol. 29, no. 8, pp. 749758,2020

[58] D. Babu, G. Leclercq, R. Motterlini, and R. A. Lefebvre, "Differential effects of CORM-2 and CORM-401 in murine intestinal epithelial MODE-K cells under oxidative stress," Frontiers in Pharmacology, vol. 8, 2017.

[59] J. E. Kim, E. Roh, M. H. Lee et al., "Fyn is a redox sensor involved in solar ultraviolet light-induced signal transduction in skin carcinogenesis," Oncogene, vol. 35, no. 31, pp. 40914101, 2016.

[60] C. Vázquez-Carballo, M. Guerrero-Hue, C. García-Caballero et al., "Toll-like receptors in acute kidney injury," International Journal of Molecular Sciences, vol. 22, no. 2, p. 816, 2021.

[61] C. W. Lee, M. C. Chi, L. F. Hsu et al., "Carbon monoxide releasing molecule-2 protects against particulate matterinduced lung inflammation by inhibiting TLR2 and 4/ROS/NLRP3 inflammasome activation," Molecular Immunology, vol. 112, pp. 163-174, 2019.

[62] C. Chen, R. Qiu, J. Yang et al., "Lipoxin A4 restores septic renal function via blocking crosstalk between inflammation and premature senescence," Frontiers in Immunology, vol. 12, 2021.

[63] W. Yao, A. Guo, X. Han et al., "Aerosol inhalation of a hydrogen-rich solution restored septic renal function," Aging, vol. 11, no. 24, pp. 12097-12113, 2019. 